\title{
Corporate Policies with Permanent and Transitory Shocks
}

\author{
June 15, 2016
}

\begin{abstract}
We model the financing, cash holdings, and hedging policies of a firm facing financing frictions and subject to permanent and transitory cash flow shocks. We show that permanent and transitory shocks generate distinct, sometimes opposite, effects on corporate policies and use the model to develop a rich set of empirical predictions. In our model, correlated permanent and transitory shocks imply less risk, lower cash savings, and a drop in the value of credit lines. The composition of cash-flow shocks affects the cash-flow sensitivity of cash, which can be positive or negative. Optimal hedging of permanent and transitory shocks may involve opposite positions.
\end{abstract}

Keywords: Cash holdings; permanent vs. transitory shocks; financing frictions.

JEL Classification Numbers: G31, G32, G35. 
During the past two decades, dynamic corporate finance models have become part of the mainstream literature in financial economics, providing insights and quantitative guidance for investment, financing, cash management, or risk management decisions under uncertainty. Two popular cash flow environments have been used extensively in this literature. In one, shocks are of permanent nature and cash flows are governed by a geometric Brownian motion (i.e. their growth rate is normally distributed). This environment has been a cornerstone of real-options models (see e.g. McDonald and Siegel (1986) or Morellec and Schürhoff (2011)) and dynamic capital structure models (see e.g. Leland (1998) or Strebulaev (2007)). In the other, shocks are purely transitory and short-term cash flows are modeled by the increments of an arithmetic Brownian motion (i.e. cash flows are normally distributed). This has proved useful in models of liquidity management (see e.g. Décamps, Mariotti, Rochet, and Villeneuve (2011) or Bolton, Chen, and Wang (2011)) and in models of dynamic agency (see e.g. DeMarzo and Sannikov (2006) or Biais, Mariotti, Plantin, and Rochet (2007)). ${ }^{1}$

Assuming that shocks are either permanent or transitory has the effect of dramatically simplifying dynamic models. However, corporate cash flows cannot generally be fully described using solely transitory or permanent shocks. Many types of firm or market shocks are transitory and do not affect long-term prospects. Examples include temporary changes in demand, delays in costumer payments, machine breakdowns, or supply chain disruptions. But long-term cash flows also change over time due to various firm, industry, or macroeconomic shocks that are of permanent nature. Examples include changes in technology, reductions of trade barriers, or changes in consumer preferences.

By definition, permanent shocks affect not only a firm's immediate productivity and cash flows but also its future productivity and cash flows. By contrast, while purely transitory shocks affect immediate cash flows, they are uninformative about future expected profitability. Consequently, corporate policies are likely to respond differently to transitory shocks

\footnotetext{
${ }^{1}$ See Strebulaev and Whited (2012) for a recent survey of models based on permanent shocks. See MorenoBromberg and Rochet (2014) for a recent survey of liquidity models based on transitory shocks. See Biais, Mariotti, and Rochet (2013) for a recent survey of dynamic contracting models. In a recent paper, He (2009) develops a dynamic agency model with permanent shocks. Abel (2015) constitutes an example of a dynamic capital structure model with purely transitory shocks only. Bolton, Wang, and Yang (2015) constitutes an example of a real options model with permanent shocks only and financing frictions.
} 
than to permanent shocks, and corporate decisions are likely to vary with the relative importance of firms' exposure to these two sources of uncertainty. ${ }^{2}$ Our objective in this paper is therefore twofold. First, we seek to develop a dynamic framework for the cash holdings, external financing, payout, and risk management decisions of a "financially constrained" firm subject to both permanent and transitory cash flow shocks. Second, we want to use this model to shed light on existing empirical results and generate novel testable implications.

We begin our analysis by formulating a dynamic structural model in which a firm faces financing frictions, in that raising outside funds is costly, and is subject to both permanent and transitory cash flow shocks. To account for the fundamentally different nature of these shocks, we model the firm cash flows in the following way. First, cash flows are subject to profitability shocks that are permanent in nature and governed by a geometric Brownian motion, as in real options and dynamic capital structure models. Second, for any given level of profitability, cash flows are also subject to short-term shocks that expose the firm to potential losses. These short-term cash flow shocks may be purely transitory but they may also be correlated with permanent shocks. In the model, the losses due to short-term shocks can be covered either using cash holdings or by raising outside funds at a cost. The firm may also hedge its exposure to permanent and transitory shocks by investing in financial derivatives or by changing its exposure to these shocks via asset substitution. When making liquidity, financing, and hedging decisions, management maximizes shareholder value.

Using this model, we generate two sorts of implications. First, we show that a combination of transitory and permanent shocks can lead to policy choices that are in stark contrast with those in models based on a single source of risk. Second, our analysis demonstrates that transitory and permanent risks have different, often opposing, implications for corporate policies. Combining them produces implications that are consistent with a number of stylized facts and allows us to generate a rich set of testable predictions.

\footnotetext{
${ }^{2}$ Consider for example a firm facing a positive demand shock. If the shock is purely transitory and the marginal cost of production is increasing, the firm is likely to use its inventory to meet this increase in demand and, therefore, the effect of this transitory increase in demand can be spread at the production stage over several periods. This in turn implies that neither the output price nor the quantity produced will adjust too much. If instead the shock is permanent in nature, a high demand today implies a high demand in the future and the shock cannot be smoothed as much. In this case, both output and price (because the marginal cost of production will be high in the future as well) will adjust more.
} 
We highlight the main empirical implications. As in standard liquidity management models in which firms are solely exposed to transitory shocks, financing frictions generate a precautionary demand for cash in our model, since raising external capital to absorb potential losses and avoid inefficient closure is costly. A key difference with prior models, however, is that the value of the firm depends not only on its cash holdings, but also on the value of the permanent shock. Notably, a unique feature of our model is that the ratio of cash holdings over profitability (firm size) is the state variable of the firm's problem. This is consistent with the approach taken in the empirical literature (see e.g. Opler, Pinkowitz, Stulz, and Williamson (1999)), but it has not been clearly motivated by theory.

Given that the empirical literature uses a related proxy, it may not seem a notable observation that "effective cash = cash/profitability". However, this observation implies that more profitable firms hold more cash. That is, as the long-term prospects of the firm improve following positive permanent shocks, the firm becomes more valuable and finds it optimal to hoard more cash. This observation also implies that a positive permanent shock has two effects. First, it affects the denominator of the state variable. Future cash flows go up in expectation so that, holding the cash balance fixed, the firm is now more constrained. The second effect of a positive permanent shock is on the cash flow today as it affects the numerator of the state variable, making the firm richer. Intuitively, the negative effect is more important when the denominator is smaller, i.e. when the firm has more cash. By contrast, a transitory shock only affects the numerator of the state variable, so that a positive transitory shock makes the firm richer and less constrained.

We show in the paper that this relation between permanent shocks and target cash holdings has numerous implications. A first implication is that target cash holdings should decrease in correlation between short-term and permanent shocks. This is not immediately expected because two correlated shocks of transitory nature would allow for diversification if correlation decreased. So cash savings would increase in correlation between transitory shocks. Intuitively, the firm benefits from increased correlation between short-term and permanent shocks because it is then able to generate cash flows when they are needed to maintain scaled cash holdings after positive permanent shocks. A related implication is that 
an increase in the volatility of permanent cash flow shocks can also decrease target cash holdings. This effect is due to the fact that volatility in permanent cash flow shocks can help manage liquidity when short-term shocks are positively correlated with permanent shocks. Our model also predicts that when this correlation is negative, cash savings should increase with the volatilities of both permanent and transitory cash flow shocks.

Another unique prediction of our model is that target cash holdings should decrease with the growth rate of transitory shocks but increase with the growth rate of permanent shock, as an increase in the latter (respectively former) makes it more (respectively less) likely that the firm will be constrained in the future. We also find that permanent shocks have large quantitative effects on firm value and optimal policies. With our baseline parameters for example, permanent shocks increase both firm value and target cash holdings by $44 \%$.

A second set of results concerns the cash-flow sensitivity of cash. In corporate-liquidity models based solely on purely transitory shocks, the cash-flow sensitivity of cash is either zero (at the target level of cash reserves) or one (away from the target). In contrast, our model predicts that firms demonstrate a non-trivial and realistic cash-flow sensitivity of cash, due to the effects of permanent shocks on target cash holdings. In our model, this sensitivity increases with financing frictions, consistent with the available evidence. In addition, it is positive when short-term and permanent shocks are positively correlated, consistent with Almeida, Campello, and Weisbach (2004), but negative when this correlation is negative, consistent with Riddick and Whited (2009).

Turning to risk management, we show that derivatives usage should depend on whether the risk stems from transitory or permanent shocks. Specifically, if futures prices and the firm's risk are positively correlated, then hedging transitory shocks involves a short futures position while hedging permanent shocks may involve a long futures position. That is, hedging permanent shocks may involve a position not contrary but aligned to the exposure. In these instances, the firm prefers to increase cash flow volatility to benefit from the increase cash flow correlation to permanent profitability shocks.

We also show that managing risk either by derivatives or by directly selecting the riskiness of assets (i.e. asset substitution) leads to the same outcome if the risk is due to purely 
transitory shocks. However, hedging with derivatives and asset substitution are not equivalent when managing the risk from permanent shocks. This is due to the fact that asset substitution does not generate immediate cash flows whereas derivatives do. This may not matter for an unconstrained firm, but it is a fundamental difference for a financially constrained firm. One prediction of the model is thus that a firm in distress would engage asset substitution with respect to permanent shocks but not in derivatives hedging.

Another way for firms to manage their risks is to acquire financial flexibility via a credit line. Our model shows that the availability of a credit line leads to both a significant decrease in target cash holdings and a significant increase in firm value, but has little effect on equity issues. Interestingly, because the correlation between permanent and short-term shocks reduces firm risk, we also find that the firms or industries that benefit most from credit lines are those in which permanent and short-term cash flow shocks are negatively correlated.

Lastly, we show that the relation between permanent shocks and target cash holdings also implies that when firms raise outside funds, the size of equity issues is not constant, but depends on the firm's profitability. Notably, a unique prediction of our model is that more profitable firms should raise more funds when accessing financial markets.

In the last section of the paper, we consider the option to invest in our constrained firm and show that the combination of financing frictions and transitory shocks delays investment. This delay is due to two separate effects. First, the cost of external finance increases the cost of investment, making the investment opportunity less attractive and leading to an increase in the profitability level required for investment. Second, the combination of transitory shocks and financing frictions reduces the value of the firm after investment, further delaying investment. That is, the threat of future cash shortfalls increases future financing costs and reduces the value of the asset underlying the growth option, thereby leading to late exercise of the investment opportunity. We show that the effect can be quantitatively important. In our base case environment for example, investment is triggered for a profitability level that is $10 \%$ higher than in models without transitory shocks and financing frictions. ${ }^{3}$

\footnotetext{
${ }^{3}$ See the early paper of McDonald and Siegel (1986) or the recent contributions of Carlson, Fisher, and Giammarino (2004, 2010), Lambrecht (2004), Manso (2008), Grenadier and Malenko (2010), or Grenadier and Malenko (2011). Dixit and Pindyck (1994) and Stokey (2009) provide excellent surveys of this literature.
} 
Our work advances the strand of research that incorporates financing frictions into dynamic models of corporate financial decisions. Recent contributions in this literature include Bolton, Chen, and Wang (2011, 2013), Décamps, Mariotti, Rochet, and Villeneuve (2011), Gryglewicz (2011), and Hugonnier, Malamud, and Morellec (2015). A key simplifying assumption in these models is that cash flows are only subject to purely transitory shocks. That is, none of these papers has permanent shocks together with transitory shocks. We show in this paper that incorporating permanent shocks in models with financing frictions leads to a richer set of empirical predictions and helps explain corporate behavior.

As relevant as it is to analyze an integrated framework combining both transitory and permanent shocks, there are surprisingly only a few attempts in the literature addressing this problem. Gorbenko and Strebulaev (2010) consider a dynamic model without financing frictions, in which firm cash flows are subject to both permanent and transitory shocks. Their study focuses on leverage choices. Our paper instead analyzes liquidity, refinancing, risk management, and investment policies. Another important difference between the two papers is that we model transitory shocks with a Brownian process instead of a Poisson process, which allows us to get a lot of tractability. Grenadier and Malenko (2010) build a real options model in which firms are uncertain about the permanence of past shocks and have the option to learn before investing. In their model, there are no financing frictions and, as a result, no role for cash holdings and no need to optimize financing decisions.

Lastly, our paper relates to the large literature that examines the distinct effects of permanent and transitory shocks on economic outcomes. While the decomposition of shocks between transitory and permanent components has been used productively over the years in many areas of economics, it has received little attention in corporate finance. ${ }^{4}$ In a re-

\footnotetext{
${ }^{4}$ A number of asset pricing papers (see e.g. Cochrane (1994), Cohen, Gompers, and Vuolteenaho (2002), Bansal, Dittmar, and Kiku (2008), Garleanu, Kogan, and Panageas (2012a), or Garleanu, Panageas, and Yu (2012b)) use such a decomposition to analyze stock returns and risk premia on stocks. This decomposition is also used in market microstructure to analyze price efficiency (see e.g. Glosten and Harris (1988), Brennan and Subrahmanyam (1996), or Boehmer and Wu (2013)). The literature on income processes also often seeks to decompose shocks into permanent and transitory components; see e.g. Blundell, Pistaferri, and Preston (2008), Meghir and Pistaferri (2004), or Gottschalk and Moffitt (2009). The decomposition of income shocks between permanent and transitory components has found interesting applications in the life-cycle portfolio choice literature; see e.g. Cocco, Gomes, and Maenhout (2005). In the time series literature, the permanenttransitory model is known as the unobserved component decomposition, in which the permanent part is the
} 
cent empirical study, Chang, Dasgupta, Wong, and Yao (2014) decompose corporate cash flows into a transitory and a permanent component and show that this decomposition helps understand how firms allocate cash flows and whether financial constraints matter in this allocation decision. Lee and Rui (2007) show that such a decomposition also allows determining whether share repurchases are used to pay out cash flows that are potentially transitory, thus preserving financial flexibility relative to dividends. Guiso, Pistaferri, and Schivardi (2005) examine the allocation of risk between firms and their workers and show that firms absorb transitory shocks fully but insure workers against permanent shocks only partially. Lastly, Byun, Polkovnichenko, and Rebello (2016) examine the separate effects of persistent and transitory shocks on corporate savings and investment decisions. Our analysis demonstrates that the distinction between transitory and permanent shocks is relevant for the larger set of policies that are of interest to financial economists, namely investment, financing, payout, cash holdings, and risk management policies.

The paper is organized as follows. Section 1 describes the model. Section 2 solves for the value and optimal policies of a financially constrained firm. Section 3 derives the model's empirical implications with respect to cash savings. Section 4 examines risk management. Section 5 examines the effects of credit lines. Section 6 derives value of the option to invest in the firm. Section 7 concludes. Technical developments are gathered in the Appendix.

\section{$1 \quad$ Model}

\subsection{Assumptions}

Throughout the paper, agents are risk neutral and discount cash flows at a constant rate $r>0$. Time is continuous and uncertainty is modeled by a probability space $(\Omega, \mathcal{F}, \mathbb{F}, P)$ with the filtration $\mathbb{F}=\left\{\mathcal{F}_{t}: t \geq 0\right\}$, satisfying the usual conditions.

We consider a firm that owns an option to invest in a risky project. The firm has full flexibility in the timing of investment but the decision to invest is irreversible. The direct cost of investment is constant, denoted by $I>0$. The project, once completed, trend and the transitory component is named the cyclical innovation; see Hamilton (1994) chapter 17. 
produces a continuous stream of cash flows that are subject to both permanent and transitory shocks. Permanent shocks change the long-term prospects of the firm and influence cash flows permanently by affecting the productivity of assets and firm size. We denote the productivity of assets by $A=\left(A_{t}\right)_{t \geq 0}$ and assume that it is governed by a geometric Brownian motion:

$$
d A_{t}=\mu A_{t} d t+\sigma_{A} A_{t} d W_{t}^{P}
$$

where $\mu$ and $\sigma_{A}>0$ are constant parameters and $W^{P}=\left(W_{t}^{P}\right)_{t \geq 0}$ is a standard Brownian motion. In addition to these permanent shocks, cash flows are subject to short-term shocks that do not necessarily affect long-term prospects. Notably, we consider that operating cash flows $d X_{t}$ after investment are proportional to $A_{t}$ but uncertain and governed by:

$$
d X_{t}=\alpha A_{t} d t+\sigma_{X} A_{t} d W_{t}^{X}
$$

where $\alpha$ and $\sigma_{X}$ are strictly positive constants and $W^{X}=\left(W_{t}^{X}\right)_{t \geq 0}$ is a standard Brownian motion. $W^{X}$ is allowed to be correlated with $W^{P}$ with correlation coefficient $\rho$, in that

$$
\mathbb{E}\left[d W_{t}^{P} d W_{t}^{X}\right]=\rho d t, \text { with } \rho \in[-1,1] .
$$

The dynamics of cash flows can then be rewritten as

$$
d X_{t}=\alpha A_{t} d t+\sigma_{X} A_{t}\left(\rho d W_{t}^{P}+\sqrt{1-\rho^{2}} d W_{t}^{T}\right)
$$

where $W^{T}=\left(W_{t}^{T}\right)_{t \geq 0}$ is a Brownian motion independent from $W^{P}$. This decomposition implies that short-term cash flow shocks $d W_{t}^{X}$ consist of transitory shocks $d W_{t}^{T}$ and permanent shocks $d W_{t}^{P}{ }^{5}$ In what follows, we refer to $\sigma_{X}$ as the volatility of short-term shocks or, when it does not cause confusion, as the volatility of transitory cash flow shocks.

The permanent nature of innovations in $A$ implies that a unit increase or decrease in $A$ increases or decreases the expected value of each future cash flow. To illustrate this property,

\footnotetext{
${ }^{5}$ One may also interpret $W^{T}$ as a shock to cash flow and $W^{P}$ as a shock to asset value. In our model, a pure cash flow shock (cash windfall) makes the firm richer but does not make the firm's assets better. A pure shock to assets (e.g., discovery of oil reserves) improves the value of the firm's assets but does not make the firm richer today. We thank Andrey Malenko for suggesting this interpretation.
} 
it is useful to consider an environment in which the firm has a frictionless access to capital markets, as in e.g. Leland (1998) or McDonald and Siegel (1986). In this case, the value of the firm after investment $V^{F B}$ is simply the present value of all future cash flows:

$$
V^{F B}(a)=\mathbb{E}_{a}\left[\int_{0}^{\infty} e^{-r t} d X_{t}\right]=\frac{\alpha a}{r-\mu}
$$

Equation (5) shows that a shock that changes $A_{t}$ via $d W_{t}^{P}$ is permanent in the sense that a unit increase in $A_{t}$ increases all future expected levels of profitability by that unit. A shock to $W_{t}^{T}$ is transitory because, keeping everything else constant, it has no impact on future cash flows. That is, when cash flow shocks are not correlated, i.e. when $\rho=0$, short-term cash flow shocks are purely transitory and do not affect future cash flows. When cash flows shocks are perfectly correlated, i.e. when $\rho=1$, any cash flow shock impact all future cash flows. More generally, cash flow shocks are a combination of transitory and permanent shocks and the long-run response of cash flows to a current shock depends on the relative size of the two shocks.

The modeling of cash flows in (1) and (2) encompasses two popular frameworks as special cases. If $\mu=\sigma_{A}=0$, we obtain the stationary framework of dynamic agency models (see DeMarzo and Sannikov (2006) or DeMarzo, Fishman, He, and Wang (2012)) and liquidity management models (see Décamps, Mariotti, Rochet, and Villeneuve (2011), Bolton, Chen, and Wang (2011), or Hugonnier, Malamud, and Morellec (2015)). In these models, cash flow shocks are purely transitory. Adding permanent shocks in these models gives rise to two sources of dynamic uncertainty that makes corporate policies intrinsically richer.

If $\sigma_{X}=0$, we obtain the model with time-varying profitability applied extensively in dynamic capital structure models (see Goldstein, Ju, and Leland (2001), Hackbarth, Miao, and Morellec (2006), or Strebulaev (2007)) and real-options models (see Abel and Eberly (1994), Carlson, Fisher, and Giammarino (2006), or Morellec and Schürhoff (2011)). Our model with transitory and permanent shocks differs from the latter in that earnings and asset volatilities differ and innovations in current cash flows are imperfectly correlated with those in asset values. As discussed in Gorbenko and Strebulaev (2010), these features are consistent with empirical stylized facts. Another distinguishing feature is that while the 
return on invested capital is constant in these models, in that $\frac{d X_{t}}{A_{t}}=\alpha d t$, this is not the case in our model in which it is subject to uncertainty, in that $\frac{d X_{t}}{A_{t}}=\alpha d t+\sigma_{X} d W_{t}^{X}$.

Lastly, our model with permanent and transitory shocks is also related to the asset pricing models of Schwartz and Smith (2000), Garleanu, Panageas, and Yu (2012b), Kogan and Papanikolaou (2013), and Kogan and Papanikolaou (2014). Notably, Kogan and Papanikolaou (2013) and Kogan and Papanikolaou (2014) build models in which any firm's output flow is the product of an aggregate productivity shock that follows a geometric Brownian motion and of firm specific shocks that are governed by (square root) stationary processes. Garleanu, Panageas, and Yu (2012b) develop a general equilibrium model in which aggregate consumption is the product of a geometric Brownian motion that captures aggregate productivity growth (embodied technological progress) and a transitory shock that captures recurrent cyclical components of technological innovations. Schwartz and Smith (2000) develop a model for commodity prices in which the equilibrium commodity price level evolves according to a geometric Brownian motion and in which short-term deviations from this equilibrium price revert toward zero following a mean-reverting stationary process. ${ }^{6}$ Our model differs from these studies in that cash flows can be negative in our setup (whereas prices have to remain positive in their setups), consistent with the available evidence.

\subsection{Shareholders' optimization problem}

In the absence of short-term shocks, the cash flows of an active firm are given by $\alpha A_{t} d t$ and are always positive because $A$ is always positive. Short-term shocks expose the firm to potential losses, that can be covered using cash reserves or by raising outside funds.

\footnotetext{
${ }^{6}$ As shown by Schwartz and Smith (2000), empirical models of commodity prices with transitory and permanent factors outperform single-factor models with only short-term or long-term effects. See also Mirantes, Poblacion, and Serna (2015) for evidence on alternative exhaustible resource markets. Both Schwartz and Smith (2000) and Mirantes, Poblacion, and Serna (2015) use Kalman filter techniques to estimate from the time series of derivatives prices, the unobservable parameters entering the dynamics of the state variables or factors. Because of the lower frequency of the data, the empirical corporate finance papers discussed in the introduction do not rely on Kalman filter techniques. Both Chang, Dasgupta, Wong, and Yao (2014) and Lee and Rui (2007) employ the approach of Beveridge and Nelson (1981) to decompose cash flows into a transitory and a permanent component. Like the Kalman filter techniques, the Beveridge-Nelson decomposition allows evaluating the volatilities of permanent and transitory shocks as well as their correlation. Guiso, Pistaferri, and Schivardi (2005) and Byun, Polkovnichenko, and Rebello (2016) use yet different empirical frameworks that impose zero correlation between permanent and transitory shocks. Our paper demonstrates that this correlation is a key driver of the corporate response to permanent and transitory shocks.
} 
Specifically, we allow management to retain earnings inside the firm and denote by $M_{t}$ the firm's cash holdings at any time $t>0$. We consider that cash reserves earn a rate of return $r-\lambda$ inside the firm, where $\lambda>0$ is a cost of holding liquidity. We also allow the firm to increase its cash holdings or cover operating losses by raising funds in the capital markets. When raising outside funds at time $t$, the firm has to pay a proportional cost $p>1$ and a fixed cost $\phi A_{t}>0$ so that if the firm raises some amount $e_{t}$ from investors, it gets $e_{t} / p-\phi A_{t}$. As in Bolton, Chen, and Wang (2011), the fixed cost scales with firm size so that the firm does not grow out from the fixed cost. ${ }^{7}$ The net proceeds from equity issues are then stored in the cash reserve, whose dynamics evolve as:

$$
d M_{t}=(r-\lambda) M_{t} d t+\alpha A_{t} d t+\sigma_{X} A_{t}\left(\rho d W_{t}^{P}+\sqrt{1-\rho^{2}} d W_{t}^{T}\right)+\frac{d E_{t}}{p}-d \Phi_{t}-d L_{t}
$$

where $L_{t}, E_{t}$, and $\Phi_{t}$ are non-decreasing processes that respectively represent the cumulative dividend paid to shareholders, the cumulative gross external financing raised from outside investors, and the cumulative fixed cost of financing.

Equation (6) is an accounting identity that indicates that cash reserves increase with the interest earned on cash holdings (first term on the right hand side), the firm's earnings (second and third terms), and outside financing (fourth term), and decrease with financing costs (fifth term) and dividends (last term). In this equation, the cumulative gross financing raised from investors $E_{t}$ and the cumulative fixed cost of financing $\Phi_{t}$ are defined as $E_{t}=$ $\sum_{n=1}^{\infty} e_{n} 1_{\tau_{n} \leq t}$ and $\Phi_{t}=\sum_{n=1}^{\infty} \phi A_{\tau_{n}} 1_{\tau_{n} \leq t}$, for some increasing sequence of stopping times $\left(\tau_{n}\right)_{n=1}^{\infty}$ that represent the dates at which the firm raises external funds and some sequence of nonnegative random variables $\left(e_{n}\right)_{n=1}^{\infty}$ that represent the gross financing amounts. ${ }^{8}$

The firm can abandon its assets at any time after investment by distributing all of its cash to shareholders. Alternatively, it can be liquidated if its cash buffer reaches zero

\footnotetext{
${ }^{7}$ The scaling of the fixed refinancing cost can be motivated by modeling this cost as in Hugonnier, Malamud, and Morellec (2015). Suppose that new investors have some bargaining power in the division of the surplus created at refinancing. A Nash-bargaining solution would allocate a share of this surplus to new investors. As will become clear in Section 2 below, the total surplus at refinancing is linear in profitability $A_{t}$. This approach would generate a fixed refinancing cost $\phi A_{t}$ with an endogenous $\phi$.

${ }^{8}$ Technically, $\left(\left(\tau_{n}\right)_{n \geq 1},\left(e_{n}\right)_{n \geq 1}, L\right)$ belongs to the set $\mathcal{A}$ of admissible policies if and only if $\left(\tau_{n}\right)_{n \geq 1}$ is a non-decreasing sequence of $\mathbb{F}$-adapted stopping times, $\left(e_{n}\right)_{n \geq 1}$ is a sequence of nonnegative $\left(\mathcal{F}_{\tau_{n}}\right)_{n \geq 1}$-adapted random variables, and $L$ is a non-decreasing $\mathbb{F}$-adapted and right-continuous process with $L_{0} \geq 0$.
} 
following a series of negative shocks and raising outside funds to cover the shortfall is too costly. We consider that the liquidation value of assets represents a fraction $\omega<1$ of their unconstrained value $V^{F B}(a)$ plus current cash holdings. The liquidation time is then defined by $\tau_{0} \equiv\left\{t \geq 0 \mid M_{t}=0\right\}$. If $\tau_{0}=\infty$, the firm never chooses to liquidate.

The objective of management in an active firm is to choose the dividend, financing, and default policies that maximize shareholder value. (We also analyze risk management in section 4 and the initial investment decision in section 6.) There are two state variables for shareholders' optimization problem after investment: Profitability $A_{t}$ and the cash balance $M_{t}$. We can thus write this problem as:

$$
V(a, m)=\sup _{\left(L,\left(\tau_{n}\right)_{n \geq 0},\left(e_{n}\right)_{n \geq 1}\right)} \mathbb{E}_{a, m}\left[\int_{0}^{\tau_{0}} e^{-r t}\left(d L_{t}-d E_{t}\right)+e^{-r \tau_{0}}\left(\frac{\omega \alpha A_{\tau_{0}}}{r-\mu}+M_{\tau_{0}}\right)\right]
$$

The first term on the right hand side of equation (7) represents the present value of payments to incumbent shareholders until the liquidation time $\tau_{0}$, net of the claim of new investors on future cash flows. The second term represents the firm's discounted liquidation value.

\section{Model solution}

In this section, we base our analysis of shareholders' problem (7) on heuristic arguments. These arguments are formalized in the Appendix.

To solve problem (7) and find the value of an active firm facing financing frictions, we need to determine the financing, payout, and liquidation policies that maximize shareholder value after investment. Consider first financing and liquidation decisions. Because of the fixed cost of financing, it is natural to conjecture that it is optimal for shareholders to delay equity issues as much as possible. That is, if any issuance activity takes place, this must be when cash holdings drop down to zero, so as to avoid liquidation. At this point, the firm either issues shares if the fixed cost of financing is not too high or it liquidates. Consider next payout decisions. In the model, cash reserves allow the firm to reduce refinancing costs or the risk of inefficient liquidation. As a result, the benefit of an additional dollar retained in

the firm is decreasing in cash reserves. Since keeping cash inside the firm entails a constant 
opportunity cost $\lambda$ on any dollar saved, we conjecture that the optimal payout policy is characterized by a profitability-dependent target cash level $m^{*}(a)$ where the marginal cost and benefit of cash holdings are equalized and it is optimal to start paying dividends.

To verify this conjecture and solve for firm value, we first consider the region $\left(0, m^{*}(a)\right)$ over which it is optimal to retain earnings. In this region, the firm does not deliver any cash flow to shareholders and equity value satisfies:

$$
\begin{aligned}
r V(a, m)= & \mu a V_{a}(a, m)+(\alpha a+(r-\lambda) m) V_{m}(a, m) \\
& +\frac{1}{2} a^{2}\left(\sigma_{A}^{2} V_{a a}(a, m)+2 \rho \sigma_{A} \sigma_{X} V_{a m}(a, m)+\sigma_{X}^{2} V_{m m}(a, m)\right) .
\end{aligned}
$$

where $V_{x}$ denote the first-order derivative of the function $V$ with respect to $x$ and $V_{x y}$ denotes the second-order partial derivative of $V$ with respect to $x$ and $y$. The left-hand side of this equation represents the required rate of return for investing in the firm's equity. The right-hand side is the expected change in equity value in the region where the firm retains earnings. The first two terms capture the effects of changes in profitability $(\mu a)$ and cash savings $(\alpha a+(r-\lambda) m)$ on equity value. The last term captures the effects of volatility in cash flows and productivity. In our model with permanent and transitory shocks, changes in productivity affect not only the value of the firm but also the value of cash reserves to shareholders in that $V_{a m}(a, m) \neq 0$.

Equation (9) is solved subject to the following boundary conditions. First, when cash holdings exceed the target level $m^{*}(a)$, the firm places no premium on internal funds and it is optimal to make a lump sum payment $m-m^{*}(a)$ to shareholders. As a result, we have

$$
V(a, m)=V\left(a, m^{*}(a)\right)+m-m^{*}(a)
$$

for all $m \geq m^{*}(a)$. Substracting $V\left(a, m^{*}(a)\right)$ from both sides of this equation, dividing by $m-m^{*}(a)$, and taking the limit as $m$ tends to $m^{*}(a)$ yields the condition

$$
V_{m}\left(a, m^{*}(a)\right)=1
$$

As $V$ is assumed to be $C^{2}$ across the boundary function $m^{*}(a)$, condition (10) in turn implies 
the high-contact condition (see Dumas (1992)):

$$
V_{m m}\left(a, m^{*}(a)\right)=0
$$

that determines the location of the optimal dividend boundary function.

When the fixed cost of external finance $\phi$ is not too large, the firm raises funds every time its cash buffer is depleted. In this case, the value-matching condition at zero is

$$
V(a, 0)=V(a, \bar{m}(a))-p \bar{m}(a)-p \phi a
$$

so that the value of shareholders' claim when raising outside financing is equal to the continuation value of equity (first term on the right-hand side) net of the claim of new investors on future cash flows (second term) and issuance costs (third term). The value-maximizing issue size $\bar{m}(a)$ is then determined by the first-order condition:

$$
V_{m}(a, \bar{m}(a))=p
$$

which ensures that the marginal cost of outside funds is equal to the marginal benefits of cash holdings at the post-issuance level of cash reserves. An important implication of equation (13) is that the optimal size of equity issues is not constant as in previous contributions, but depends on the firm's productivity. Lastly, when the fixed cost of financing makes an equity issue unattractive, liquidation is optimal at $m=0$ and we have:

$$
V(a, 0)=\frac{\omega \alpha a}{r-\mu}
$$

While there are two state variables for shareholders' optimization problem (9)-(14), this problem is homogeneous of degree one in $a$ and $m$. We can thus write:

$$
V(a, m)=a V(1, m / a) \equiv a F(c)
$$

where $c \equiv \frac{m}{a}$ represents the scaled cash holdings of the firm and $F(c)$ is the scaled value function. Using this observation, the boundary conditions can be rewritten in terms of the 
scaled value function $F$ as a standard free boundary problem with only one state variable, the scaled cash holdings of the firm $c$ that evolve between the liquidation/refinancing trigger located at zero and the payout trigger $c^{*}$.

Importantly, this scaling feature of the model also permits a better understanding of the distinct effects of permanent and transitory shocks on optimal policies and firm value. Notably, an application of Girsanov's theorem and Itô's formula implies that the dynamics of scaled cash holdings are given by (see the Appendix):

$$
d C_{t}=\left(\alpha+C_{t}(r-\lambda-\mu)\right) d t+\sigma_{X} \sqrt{1-\rho^{2}} d W_{t}^{T}+\left(\rho \sigma_{X}-C_{t} \sigma_{A}\right) d \tilde{W}_{t}^{P}+\frac{d E_{t}}{p A_{t}}-\frac{d \Phi_{t}+d L_{t}}{A_{t}}
$$

Consistent with equations (1), (2), and (6), equation (16) shows that the average scaled cash flow per unit of time is $\alpha d t$ and that the rate of return earned on scaled cash reserves per unit of time is $(r-\lambda-\mu) d t$, where $\mu$ represents the expected growth rate of the scaling factor. The term

$$
\Sigma(c)=\sigma_{X}^{2}\left(1-\rho^{2}\right)+\left(\rho \sigma_{X}-C_{t} \sigma_{A}\right)^{2},
$$

represents the squared volatility of scaled cash holdings. The first term on the right hand side of (17) is constant and reflects the impact of transitory shocks. The second term is a function of $c$ and reflects the impact of permanent shocks. In models with transitory shocks only, the volatility of cash holdings is constant and coincides with the volatility $\sigma_{X}$ of cash flows (this corresponds to the case $\sigma_{A}=\mu=\rho=0$ ). Incorporating permanent shocks in these models leads to an endogenous volatility that depends on the level of scaled cash holdings $c$ and the correlation coefficient $\rho$ between short-term and permanent shocks.

The key observation is that a permanent shock has two, possibly opposing, effects on scaled cash holdings. Specifically, a positive permanent shock $\left(d \tilde{W}_{t}^{P}>0\right)$ moves the firm's cash reserves closer to the target cash level $c^{*}$ when $\rho>0\left(\rho \sigma_{X} d \tilde{W}_{t}^{P}>0\right)$ and away from $c^{*}$ when $\rho<0\left(\rho \sigma_{X} d \tilde{W}_{t}^{P}<0\right)$. At the same time, a positive permanent shock makes assets more valuable, leading to an increase in the precautionary demand for cash and to a greater distance between current cash reserves and the target level $\left(-c \sigma_{A} d \tilde{W}_{t}^{P}<0\right)$. This latter 
effect is the strongest when the positive permanent shock has little effect on the cash flow today (low $\rho$ ) and if the firm is relatively cash rich (high $c$ ). The two effects of permanent shocks imply a potentially non-monotonic behavior of the volatility of scaled cash holdings with respect to the deep parameters of the model $\rho, \sigma_{X}$, and $\sigma_{A}$. As we show below, this observation leads to new comparative statics results on target cash holdings (see section 3) and has important consequences for risk management (see section 4) and the value of credit lines (see section 5). Lastly, as in previous models with financing frictions, positive transitory shocks (i.e. $d W_{t}^{T}>0$ ) have no effects on future cash flows and unambiguously bring the firm closer to the target level of cash reserves $c^{*}$, making the firm richer and less constrained.

We can now follow the same steps as above to derive shareholders' modified optimization problem after investment. Using equation (15), we have that $V_{m}(a, m)=F^{\prime}(c), V_{m m}(a, m)=$ $\frac{1}{a} F^{\prime \prime}(c), V_{a}(a, m)=F(c)-c F^{\prime}(c), V_{a a}(a, m)=\frac{c^{2}}{a} F^{\prime \prime}(c)$, and $V_{a m}(a, m)=-\frac{c}{a} F^{\prime \prime}(c)$. Plugging these expressions in equation (9) shows that the scaled value function $F(c)$ satisfies

$$
(r-\mu) F(c)=(\alpha+c(r-\lambda-\mu)) F^{\prime}(c)+\frac{1}{2}\left(\sigma_{A}^{2} c^{2}-2 \rho \sigma_{A} \sigma_{X} c+\sigma_{X}^{2}\right) F^{\prime \prime}(c),
$$

in the earnings retention region $\left(0, c^{*}\right)$. The left hand side of this equation represents the rate of return required by shareholders for investing in the firm. The right hand side represents the expected change in the scaled value function in the region where the firm retains earnings. Consistent with equation (16), the expression $\alpha+c(r-\mu-\lambda)$ in front of $F^{\prime}(c)$ corresponds to the sum of the mean cash flow rate $\alpha$ and the instantaneous return on cash holdings per unit of invested capital $c(r-\mu-\lambda)$. The expression in front of $F^{\prime \prime}(c)$ corresponds to the squared volatility $\Sigma(c)$ of the scaled cash holdings process $C_{t}$, defined in equation (17).

Equation (18) is solved subject to the following boundary conditions. First, in the payout region $c>c^{*}$, the firm pays out any cash in excess of $c^{*}$ and we have

$$
F(c)=F\left(c^{*}\right)+c-c^{*}
$$

Subtracting $F\left(c^{*}\right)$ from both sides of this equation, dividing by $c-c^{*}$, and taking the limit as $c$ tends to $c^{*}$ shows that $F(c)$ satisfies the following value-matching and high-contact 
conditions at the optimal payout trigger $c^{*}$ :

$$
\begin{aligned}
& F^{\prime}\left(c^{*}\right)=1, \\
& F^{\prime \prime}\left(c^{*}\right)=0 .
\end{aligned}
$$

Additionally, when the firm runs out of cash, shareholders can either refinance or liquidate assets. As a result, the scaled value function satisfies

$$
F(0)=\max \left(\max _{c \in[0, \infty)}(F(c)-p(c+\phi)) ; \frac{\omega \alpha}{r-\mu}\right) .
$$

When refinancing at zero is optimal, scaled cash holdings after refinancing $\bar{c}$ are given by the solution to the first-order condition:

$$
F^{\prime}(\bar{c})=p .
$$

Before solving shareholders' problem, we can plug the value-matching and high-contact conditions (20)-(21) in equation (18) to determine the value of the firm at the target level of scaled cash holdings $c^{*}$. This shows that equity value satisfies

$$
V\left(a, m^{*}(a)\right)=a F\left(c^{*}\right)=\frac{\alpha a}{r-\mu}+\left(1-\frac{\lambda}{r-\mu}\right) m^{*}(a) .
$$

Together with equation (5), equation (24) implies that equity value in a constrained firm holding $m^{*}(a)$ units of cash is equal to the first best equity value minus the cost of holding liquidity, which is the product of the target level of cash holdings $m^{*}(a)$ and the present value of the unit cost of holding cash $\frac{\lambda}{r-\mu}$.

The following proposition summarizes these results and characterizes shareholders' optimal policies and value function after investment.

Proposition 1. Consider a firm facing financing frictions $(\phi>0, p>1)$, costs of carrying cash $(\lambda>0)$, and imperfectly correlated permanent and short-term cash flow shocks $(\rho<1)$.

1. The value of the firm, $V(m, a)$ solving problem (7), satisfies the relation $V(m, a)=$ aF $\left(\frac{m}{a}\right)$, where $\left(F, c^{*}\right)$ is the unique solution to the system (18)-(23). 
2. The function $F(c)$, where $c \equiv \frac{m}{a}$, is increasing and concave over $(0, \infty) . F^{\prime}(c)$ is greater than one in the earnings retention region $\left(0, c^{*}\right)$, where $c^{*} \equiv \inf \left\{c>0 \mid F^{\prime}(c)=1\right\}$, and equal to 1 in the payout region $c \in\left[c^{*}, \infty\right)$.

3. If financing frictions are large, it is never optimal to issue new shares after investment, $F(0)=\frac{\omega \alpha}{r-\mu}$, and the firm is liquidated as soon as it runs out of cash.

4. If financing frictions are low, $F(0)>\frac{\omega \alpha}{r-\mu}$ and it is optimal to raise a dollar amount $e_{n}^{*}=p(\bar{c}+\phi) A_{\tau_{n}}$ at each time $\tau_{n}$ at which the firm runs out of cash, where $\bar{c} \equiv\left(F^{\prime}\right)^{-1}(p)$.

5. When $m \in\left(0, m^{*}(a)\right)$, the marginal value of cash is increasing in profitability. Any cash held in excess of the dividend boundary function $m^{*}(a)=c^{*} a$ is paid out to shareholders. Payments are made to shareholders at each time $\tau$ satisfying $M_{\tau}=c^{*} A_{\tau}$.

Proposition 1 delivers several results. First, as in previous dynamic models with financing frictions (such as Bolton, Chen, and Wang (2011) or Décamps, Mariotti, Rochet, and Villeneuve (2011)), firm value is concave in cash reserves. This implies that it is never optimal for shareholders to increase the risk of (scaled) cash reserves. Indeed, if the firm incurs a series of shocks that deplete its cash reserves, it incurs some cost to raising external funds. To avoid these costs and preserve equity value, the firm behaves in a risk-averse fashion.

Second, Proposition 1 shows that when the cost of external funds is not too high, it is optimal for shareholders to refinance when the firm's cash reserves are depleted. In addition, the optimal issue size depends on the profitability of assets at the time $\tau_{n}$ of the equity issue and is given by $e_{n}^{*}=p(\bar{c}+\phi) A_{\tau_{n}}$. Thus, a unique feature of our model is that the size of equity issues is not constant. Rather, more profitable firms make larger equity issues.

Third, prior research has shown that the marginal value of cash should be decreasing in cash reserves and increasing in financing frictions (see e.g. Décamps, Mariotti, Rochet, and Villeneuve (2011)). Proposition 1 shows that the marginal value of cash should also be increasing in profitability (firm size), in that $V_{a m}>0$. We show below that this result has important consequences for optimal cash holdings and risk management policies.

Fourth, Proposition 1 shows that cash reserves are optimally reflected down at $m^{*}(a)=$ $c^{*} a$. When cash reserves exceed $m^{*}(a)$, the firm is fully capitalized and places no premium on 
internal funds, so that it is optimal to make a lump sum payment $m-m^{*}(a)$ to shareholders. As we show in section 3.1 below, the desired level of reserves results from the trade-off between the cost of raising funds and the cost of holding liquid reserves and reflects the firm's exposure to permanent and transitory cash flow shocks.

\section{Model analysis}

\subsection{Optimal cash holdings and the value of a constrained firm}

Do transitory and permanent shocks have qualitatively the same effects on firm value and optimal policies? To answer this question, we examine in this section the effects of the parameters driving the dynamics of transitory and permanent shocks on the value of a constrained firm $F(c)$ and target cash holdings $c^{*}$.

The following lemma derives comparative statics with respect to an exogenous parameter $\theta \in\left\{\sigma_{X}, \sigma_{A}, \rho, \phi, p, \alpha, \mu\right\}$, on which we will base our empirical predictions. To make the dependence of $F$ and $c^{*}$ on $\theta$ explicit, we write $F=F(., \theta)$ and $c^{*}=c^{*}(\theta)$. Focusing on the refinancing case (results for the liquidation case are in the Appendix), we have that:

Proposition 2. The following holds:

1. Firm value satisfies

$$
\frac{\partial F}{\partial p}(c, p)<0, \frac{\partial F}{\partial \phi}(c, \phi)<0, \frac{\partial F}{\partial \mu}(c, \mu)>0, \frac{\partial F}{\partial \alpha}(c, \alpha)>0, \text { and } \frac{\partial F}{\partial \rho}(c, \rho)>0 .
$$

2. Target cash reserves satisfy

$$
\frac{d c^{*}(p)}{d p}>0, \frac{d c^{*}(\phi)}{d \phi}>0, \frac{d c^{*}(\mu)}{d \mu}>0, \frac{d c^{*}(\alpha)}{d \alpha}<0, \text { and } \frac{d c^{*}(\rho)}{d \rho}<0
$$

Several results follow from Proposition 2. First, firm value decreases and the target level of cash reserves increases with financing frictions ( $p$ and $\phi)$, as in models with purely transitory shocks only (see e.g. Décamps, Mariotti, Rochet, and Villeneuve (2011) or Hugonnier, Malamud, and Morellec (2015)). Second, both the growth rate of profitability $\mu$ and the 
mean cash flow rate $\alpha$ increase firm value. Interestingly, however, while target cash reserves increase with the growth rate of the permanent shock $\mu$, they decrease with the mean cash flow rate $\alpha$. To understand these effects, it is important to recall that the trend in the dynamics of scaled cash holdings $\left(\alpha+C_{t}(r-\lambda-\mu)\right)$ is increasing $\alpha$ and decreasing $\mu$. When the mean cash flow rate $\alpha$ increases, it becomes less likely that scaled cash holdings fall to zero and the firm optimally decreases its target cash level. However, when the growth rate $\mu$ of permanent shocks increases, scaled cash holdings decrease and it becomes more likely that they will reach zero, implying an increase of optimal scaled cash holdings. This in turn implies that our model has opposite predictions for the effects of an increase in the mean of transitory and permanent shocks on target cash holdings.

Third, Proposition 2 shows that the effect of correlation between short-term and permanent shocks $\rho$ on firm value is unambiguously positive. It is not immediately expected that firm value increases in $\rho$. Indeed, if the firm faced two shocks of transitory nature, the result would be opposite. Lower correlation of two transitory shocks would allow for diversification and firm value would decrease in correlation between transitory shocks. Our result shows that correlation between short-term and permanent shocks works differently.

To understand why firm value increases with the correlation between short-term and permanent shocks $\rho$, think about a firm hit by a positive permanent shock. Its expected size increases and, in order to maintain scaled cash holdings, the firm needs to increase (unscaled) cash holdings. If short-term shocks are positively correlated with permanent shocks, in expectation cash flows temporarily increase and the firm has the means to increase cash holdings. ${ }^{9}$ If short-term shocks are not correlated with permanent shocks, the firm may not be able to do so and its value will benefit less from the positive permanent shock. It is also interesting to observe that an increase in the correlation between shocks decreases target cash holdings. The intuition for the negative effect of the correlation between short-term

\footnotetext{
${ }^{9}$ In general, the correlation coefficient $\rho$ between short-term and permanent cash flow shocks can be positive or negative. Examples of a negative correlation include decisions to invest in R\&D or to sell assets. When the firm sells assets today, it experiences a positive cash flow shock. However, it also decreases permanently future cash flows. Examples of positive correlation include price changes due to the exhaustion of existing supply of a commodity or improving technology for the production and discovery of a commodity. Chang, Dasgupta, Wong, and Yao (2014) estimate that for firms listed in the Compustat Industrial Annual files between 1971 and 2011, the correlation between short-term and permanent cash flow shocks is negative.
} 
and permanent shocks is that with higher correlation the firm gets positive cash flows shocks when they are needed to maintain scaled cash holdings, so that target cash holdings can be lower. This prediction is unique to our model.

The effects of volatility on firm value and cash holdings are more difficult to characterize. Applying Proposition 7 in the Appendix, we can measure the effect of the volatility of shortterm shocks $\sigma_{X}$ on the (scaled) value of an active firm. Keeping correlation $\rho$ constant, $\sigma_{X}$ is also a measure of the volatility of transitory shocks. Notably, we have that:

$$
\frac{\partial F}{\partial \sigma_{X}}\left(c, \sigma_{X}\right)=\mathbb{E}_{c}\left[\int_{0}^{\tau_{0}} e^{-(r-\mu) t}\left(-\rho \sigma_{A} C_{t^{-}}+\sigma_{X}\right) \frac{\partial^{2} F}{\partial c^{2}}\left(C_{t^{-}}, \sigma_{X}\right) d t\right]
$$

Given that the function $F(c)$ is concave, we have that $\frac{\partial F(c)}{\partial \sigma_{X}}<0$ if $\rho \leq 0$. For $\rho \in(0,1)$, the sign of $\frac{\partial F(c)}{\partial \sigma_{X}}$ is not immediately clear. However, numerical simulations suggest that the effect of increased volatility of short-term shocks on firm value is negative, consistent with previous literature (see e.g. Décamps, Mariotti, Rochet, and Villeneuve (2011)). ${ }^{10}$

Consider next the effect of the volatility of permanent shocks on firm value. Applying Proposition 7 in the Appendix, we have:

$$
\frac{\partial F}{\partial \sigma_{A}}\left(c, \sigma_{A}\right)=\mathbb{E}_{c}\left[\int_{0}^{\tau_{0}} e^{-(r-\mu) t}\left(\sigma_{A} C_{t^{-}}-\rho \sigma_{X}\right) C_{t^{-}} \frac{\partial^{2} F}{\partial c^{2}}\left(C_{t^{-}}, \sigma_{A}\right) d t\right]
$$

Clearly, this equation shows that $\frac{\partial F(c)}{\partial \sigma_{A}}<0$ if $\rho \leq 0$. When $\rho \in(0,1)$, the effect of an increase in the volatility of permanent shocks on firm value is ambiguous. The reason is that firm value decreases in the volatility of scaled cash holdings $c$, and $\sigma_{A}$ may either increase or decrease this volatility. Indeed, as shown by equation (16), the instantaneous variance of $c$ is $\sigma_{A}^{2} c^{2}-2 \rho \sigma_{A} \sigma_{X} c+\sigma_{X}^{2}$. Its derivative with respect to $\sigma_{A}$ is $2 \sigma_{A} c^{2}-2 \rho \sigma_{X} c$. This in turn implies that the volatility of permanent shocks may increase or decrease the volatility of scaled cash holdings, and hence target cash holdings, depending on the level of the cash reserve $c=\frac{m}{a}$ relative to $\rho \frac{\sigma_{X}}{\sigma_{A}}$. That is, because liquidity management aims at reducing firm risk, target cash holdings increase with $\sigma_{A}$ when $c \geq \rho \frac{\sigma_{X}}{\sigma_{A}}$.

\footnotetext{
${ }^{10}$ It is clear from equation (25) that $c^{*} \leq \frac{\sigma_{X}}{\rho \sigma_{A}}$ is a sufficient condition for the negative derivative with respect to $\sigma_{X}$ when $\rho>0$. The inequality $c^{*} \stackrel{\rho \sigma_{A}}{\leq} \frac{\sigma_{X}}{\rho \sigma_{A}}$ always holds at our baseline parameter values. Despite extensive simulation, we have not been able to find any instance of a positive effect of $\sigma_{X}$ on $F$ when $\rho>0$.
} 
To examine the effects of volatility on target cash holdings, we can use the relation:

$$
\frac{d c^{*}(\theta)}{d \theta}=-\frac{r-\mu}{\lambda}\left(\frac{\partial F}{\partial \theta}\left(c^{*}(\theta), \theta\right)+c^{*}(\theta) \frac{\partial\left[\frac{\lambda}{r-\mu}\right]}{\partial \theta}-\frac{\partial\left[\frac{\alpha}{r-\mu}\right]}{\partial \theta}\right) .
$$

It follows from the previous discussion on the effects of $\sigma_{X}$ and $\sigma_{A}$ on $F(c)$ that $\frac{\partial c^{*}}{\partial \sigma_{X}}>0$ and $\frac{\partial c^{*}}{\partial \sigma_{A}}>0$ if $\rho \leq 0$, and $\frac{\partial c^{*}}{\partial \sigma_{X}}>0$ and $\frac{\partial c^{*}}{\partial \sigma_{A}} \gtrless 0$ if $\rho \in(0,1)$. Interestingly, Chang, Dasgupta, Wong, and Yao (2014) decompose corporate cash flows into a transitory and a permanent component and show that for firms listed in the Compustat Industrial Annual files between 1971 and 2011, the correlation between these shocks is negative. Using the same date, Byun, Polkovnichenko, and Rebello (2016) find that "firms increase cash savings in response to increased uncertainty arising from both persistent and transitory shocks." This empirical result is consistent with our prediction that cash holdings should increase with $\sigma_{A}$ and $\sigma_{X}$ when $\rho<0$. It is again interesting to observe that our model predicts that if $\rho$ was sufficiently positive in some industries, then the relation between cash savings and the volatility of permanent shocks $\sigma_{A}$ could become negative.

For completeness, Figure 1 plots target cash holdings $c^{*}$ and the optimal issue size $\bar{c}$ as functions of the volatilities of short-term shocks $\sigma_{X}$ and permanent shocks $\sigma_{A}$, the correlation between shocks $\rho$, the fixed and proportional financing $\operatorname{costs} \phi$ and $p$, and the carry cost of cash $\lambda$. These panels confirm the above comparative statics results. They also show that the size of equity issues should increase with the fixed cost of financing (since the benefit of issuing equity must exceed $\phi$ ) and decrease with the proportional cost of financing (since firm value is concave and $F^{\prime}(\bar{c})=p$ ). As in prior models, the effects of the other parameters on the optimal size of equity issues $\bar{c}$ mirror those of these parameters on target cash holdings.

The question we ask next is whether permanent shocks have non-trivial quantitative effects. ${ }^{11}$ To answer this question, we examine the predictions of the model for the firm's financing and cash holdings policies. To do so, we select parameters that match previous studies. Notably, following models with transitory shocks only (e.g. Bolton, Chen, and Wang (2013)), we set the risk-free rate to $r=3 \%$, the mean cash flow rate to $\alpha=0.18$,

\footnotetext{
${ }^{11}$ The analysis presented here is not intended to substitute for a more detailed quantitative study, but serves to highlight the effects of including or omitting permanent shocks in dynamic corporate finance models.
} 
Figure 1: Optimal cash holdings and issue size.
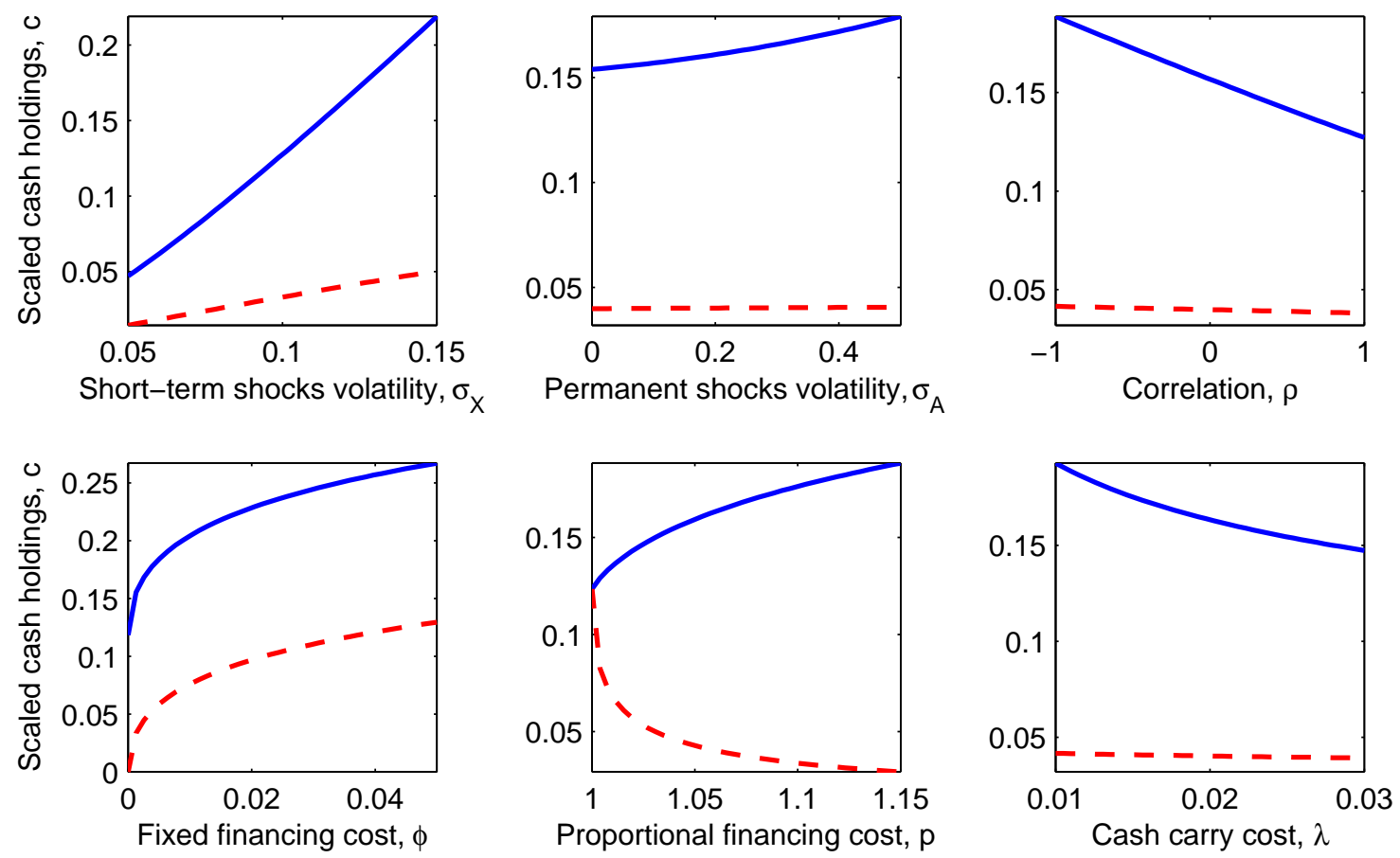

Notes. Figure 1 plots target cash holdings $c^{*}$ (solid curves) and the scaled issuance size $\bar{c}$ (dashed curves) in the refinancing case. Input parameter values are given in Table 1.

the volatility of short-term shocks to $\sigma_{X}=0.12$, and the carry cost of cash to $\lambda=0.02$. Financing costs are set equal to $\phi=0.002$ and $p=1.06$, implying that the firm pays a financing cost of $10.4 \%$ when issuing equity. The parameters of the permanent shocks are set equal to $\mu=0.01$ and $\sigma_{A}=0.25$, consistent with Morellec, Nikolov, and Schürhoff (2012). The correlation between transitory and permanent shocks is set to $\rho=-0.21$, consistent with Chang, Dasgupta, Wong, and Yao (2014). ${ }^{12}$ Lastly, we base the value of liquidation

\footnotetext{
${ }^{12}$ While the correlation coefficient $\rho$ affects the persistence of cash flows, it should not be confused with the cash flow autocorrelation. We have simulated daily cash flows for 100 firms over 1000 years using our cash flow specification (4) and our base case parameters and run an $\operatorname{AR}(1)$ regression of annual cash flows $(C F(t+1)=\alpha+\beta C F(t)+\epsilon(t+1))$. The coefficient $\beta$ obtained in the AR(1) regression on our simulated data is 0.6526 , which matches the empirical estimates of 0.65 obtained by Frankel and Litov (2009) for the autocorrelation of annual cash flows for COMPUSTAT firms between 1984 and 2004. In our model, changing the correlation coefficient $\rho$ changes autocorrelation, but autocorrelation of cash flows is mostly driven by the scale of the permanent shock relative to the transitory shock.
} 
Table 1: Parameter values and variables

\begin{tabular}{lclcc}
\hline Variable & Symbol & Parameter & Symbol & Value \\
\hline Cash holdings & $M$ & Growth rate of asset productivity & $\mu$ & 0.01 \\
Scaled cash holdings & $C$ & Mean rate of cash flows & $\alpha$ & 0.18 \\
Asset productivity/size & $A$ & Volatility of permanent shocks & $\sigma_{A}$ & 0.25 \\
Cumulative cash flows & $X$ & Volatility of short-term shocks & $\sigma_{X}$ & 0.12 \\
Cumulative payout & $L$ & Correlation between shocks & $\rho$ & -0.21 \\
Cumulative external financing & $E$ & Riskfree rate & $r$ & 0.03 \\
Cumulative fixed financing cost & $\Phi$ & Carry cost of liquidity & $\lambda$ & 0.02 \\
Active firm value & $V$ & Proportional financing cost & $p$ & 1.06 \\
Scaled active firm value & $F$ & Fixed financing cost & $\phi$ & 0.002 \\
Investment option value & $G$ & Asset liquidation-value ratio & $\omega$ & 0.55 \\
Payout boundary & $c^{*}$ & Investment cost & $I$ & 10 \\
Financing target & $\bar{c}$ & Credit line spread & $\xi$ & 0.015 \\
\hline
\end{tabular}

costs on Glover (2016) and set $1-\omega=45 \%$.

Figure 2 shows the effects of introducing time-varying profitability via permanent shocks in a dynamic model with financing frictions. To better understand the sources of changes, separate plots are shown in which we first introduce a positive drift only (Panel A with $\mu=0.01$ and $\sigma_{A}=0$ ), then a positive volatility only (Panel B with $\mu=0$ and $\sigma_{A}=0.25$ ), and finally in which we combine both drift and volatility effects (Panel $\mathrm{C}$ with $\mu=0.01$ and $\left.\sigma_{A}=0.25\right)$. Introducing a positive growth in cash flows is similar to introducing a capital stock that appreciates deterministically at the rate $\mu$. As a result of this drift in cash flows, firm value is increased by $46 \%$ at the target level of cash reserves. However, target (scaled) cash holdings are much less affected by the introduction of a permanent drift (an increase by less than $5 \%$ ) as risk does not change.

By contrast, Figure 2 shows that adding volatility in $A$ changes the target level of scaled cash holdings significantly without having a material effect on the value of the firm. In our base case parametrization for example, optimal cash holdings rise by $34 \%$ since the volatility of scaled cash holdings is increased by the introduction of volatility in $A$ (in that we have $\sqrt{\sigma_{A}^{2} c^{2}-2 \rho \sigma_{A} \sigma_{X} c+\sigma_{X}^{2}}>\sigma_{X}$ over the relevant range). As shown by the figure, the joint effect of $\mu$ and $\sigma_{A}$ is substantial on both firm value (an increase by $44 \%$ at the target) and target cash holdings (an increase by 44\%). 
Figure 2: The effects of permanent shocks with liquidation
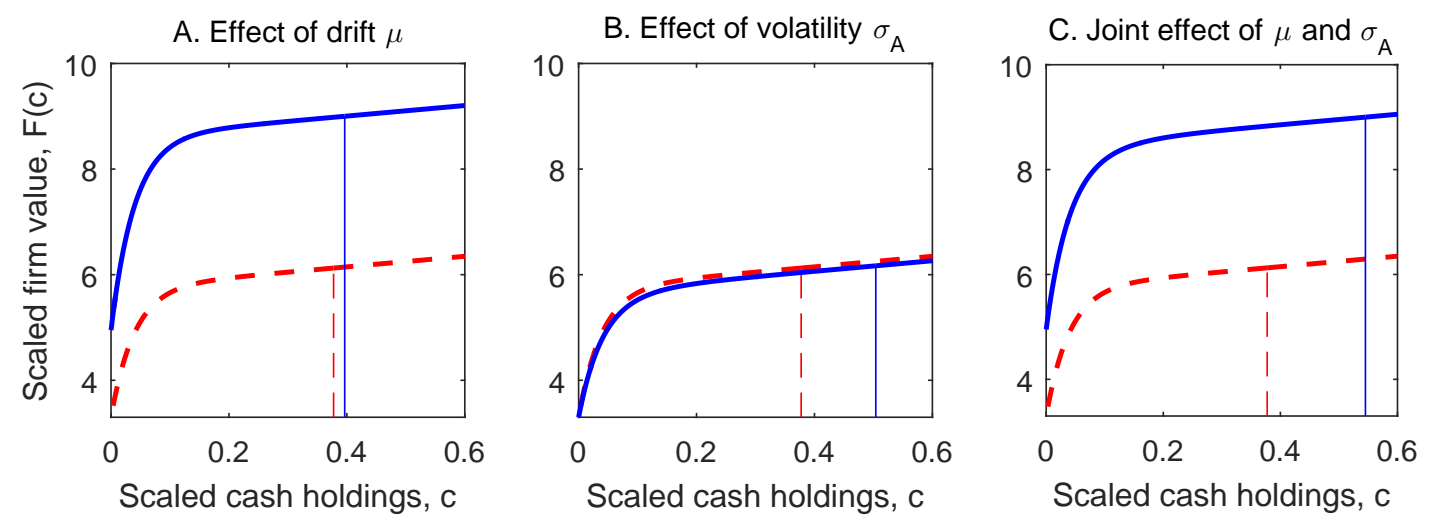

Notes. Figure 2 plots firm value and target cash holdings in the liquidation case. The dashed curves represent the case with only transitory shocks $\left(\sigma_{A}=\mu=0\right)$ in all the panels. The solid curves are with permanent shocks, with $\mu=0.01$ and $\sigma_{A}=0$ in Panel $\mathrm{A}, \mu=0$ and $\sigma_{A}=0.25$ in Panel B, and $\mu=0.01$ and $\sigma_{A}=0.25$ in Panel C. In all the cases, the vertical lines depict the target scaled cash holdings $c^{*}$. Input parameter values are given in Table 1.

Figure 3 shows that similar results obtain in the refinancing case. Again the drift $\mu$ of permanent shocks affects mostly the value function and has little impact on optimal policies. The volatility $\sigma_{A}$ of permanent shocks significantly affects optimal policies but has almost no impact on the value function.

\subsection{Cash-flow sensitivity of cash}

Corporate liquidity models featuring solely transitory shocks characterize optimal cash holdings and dividend policies using a constant target level of cash holdings (see e.g. Bolton, Chen, and Wang (2011), Décamps, Mariotti, Rochet, and Villeneuve (2011), or Hugonnier, Malamud, and Morellec (2015)). This generates the prediction that firms at the target distribute all positive cash flows or, equivalently, that cash holdings are insensitive to cash flows. As firms off the target retain all earnings, the predicted propensity to save from cash flows is either one or zero. Our model generates a more realistic firm behavior at the target cash level and provides an explicit measure of the cash-flow sensitivity of cash. 
Figure 3: The effects of permanent shocks with refinancing
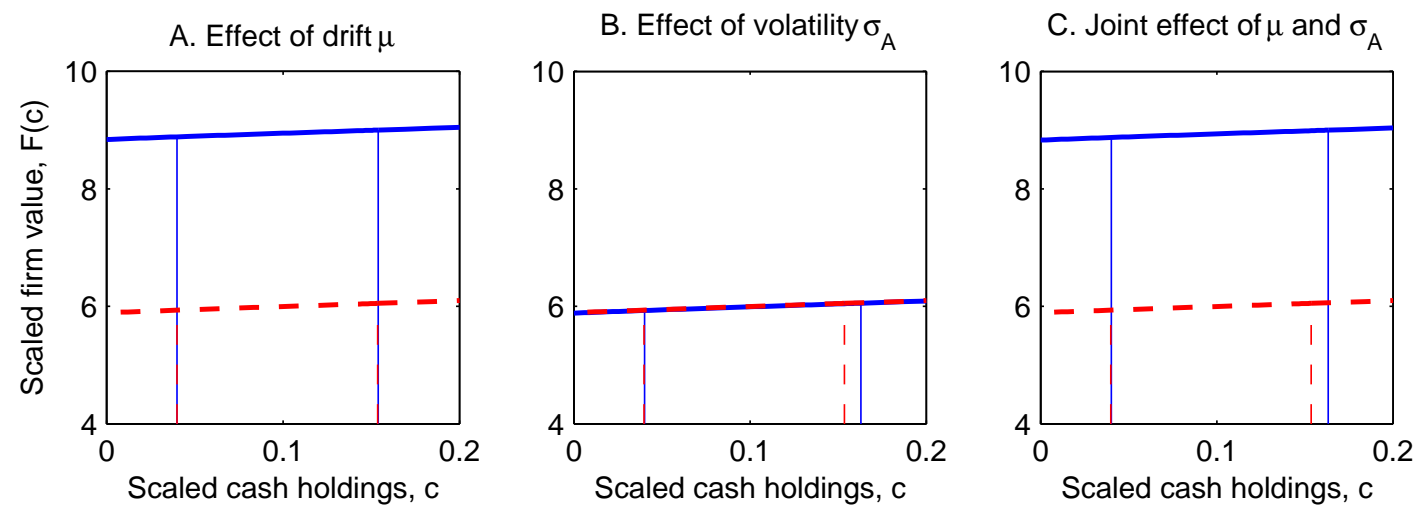

Notes. Figure 3 plots firm value and target cash holdings in the refinancing case. The dashed curves represent the case with only transitory shocks $\left(\sigma_{A}=\mu=0\right)$ in all panels. The solid curves are with permanent shocks, with $\mu=0.01$ and $\sigma_{A}=0$ in Panel A, $\mu=0$ and $\sigma_{A}=0.25$ in Panel $\mathrm{B}$, and $\mu=0.01$ and $\sigma_{A}=0.25$ in Panel C. The vertical lines depict the scaled issue size $\bar{c}$ and target scaled cash holdings $c^{*}$. Input parameter values are as in Table 1.

To illustrate this feature, suppose that cash holdings are at the target level so that $M_{t}=$ $c^{*} A_{t}$. For our model, this is a most relevant assumption since the bulk of the probability mass of the stationary distribution of cash holdings is at the target level. ${ }^{13}$ Upon the realization of a cash flow shock $d X_{t}$, profitability $A_{t}$ changes in expectation by

$$
\mathbb{E}\left[d A_{t} \mid d X_{t}\right]=\mu A_{t} d t+\sigma_{A} A_{t} \frac{\rho}{\sigma_{X} A_{t}}\left(d X_{t}-\alpha A_{t} d t\right)
$$

Target cash holdings then change to $c^{*}\left(A_{t}+d A_{t}\right)$ and this change conditional on $d X_{t}$ can be expressed as

$$
\mathbb{E}\left[c^{*} d A_{t} \mid d X_{t}\right]=c^{*}\left(\mu-\frac{\alpha \rho \sigma_{A}}{\sigma_{X}}\right) A_{t} d t+\frac{\rho \sigma_{A} c^{*}}{\sigma_{X}} d X_{t} .
$$

\footnotetext{
${ }^{13}$ The concentration of cash holdings close to the target level arises because the optimal payout policy is to reflect cash reserves at the target and the optimal financing policy is to go back to the target level of cash reserves when accessing external capital markets. See also Figure 5 in Bolton, Chen, and Wang (2011). Note that in these models we can only compute the stationary distribution of cash holdings for the refinancing case since, in the liquidation case, the firm liquidates with probability 1.
} 
The sensitivity of target cash holdings to cash flow shocks is then captured by $\epsilon$ defined by

$$
\epsilon=\frac{\rho \sigma_{A} c^{*}}{\sigma_{X}} \lessgtr 0
$$

As the firm may not be able to stay at the target after a positive shock if this sensitivity exceeds 1 and may have excess cash after a negative shock if the sensitivity is less than 1, the sensitivity of actual cash holdings to positive shocks is $\epsilon_{+}=\min \{\epsilon, 1\}$ and to negative shocks is $\epsilon_{-}=\max \{\epsilon, 1\}$. It should be stressed that $\epsilon$ measures the sensitivity in expectation, as one would obtain by regressing cash flows on cash holdings. An advantage of our bi-dimensional model is that individual realizations of cash flows are not tightly linked to changes in cash holdings whenever $\rho<1$, consistent with the observed behavior of firms.

When permanent and short-term shocks are positively related (i.e. $\rho>0$ ), the sensitivity of cash holdings to cash flow shocks is driven by the positive relation between profitability and the marginal value of cash (i.e. $V_{a m}=-\frac{c}{a} F^{\prime \prime}(c) \geq 0$ ), which implies that the firm optimally retains a part of a positive cash flow shock if profitability increases. For this mechanism to work, a cash flow shock needs to be related to changes in profitability in expectation. Without permanent shocks (i.e. $\sigma_{A}=0$ ) or without correlation between permanent and short-term shocks (i.e. $\rho=0$ ), the cash-flow sensitivity of cash $\epsilon$ is zero. As shown by equation (30), the sensitivity $\epsilon$ depends directly on the parameters of transitory and permanent shocks, $\rho, \sigma_{A}$, and $\sigma_{X}$, and indirectly on the other parameters of the model via the target level of cash holdings $c^{*}$. In particular, since $c^{*}$ increases in the cost of refinancing, the cashflow sensitivity of cash increases in external financing frictions, consistent with Almeida, Campello, and Weisbach (2004) and Riddick and Whited (2009).

For firms or industries in which permanent and short-term shocks are negatively related (i.e. $\rho<0$ ), our model predicts that the cash flow sensitivity of cash should be negative. Interestingly, Chang, Dasgupta, Wong, and Yao (2014) find that for U.S. nonfinancial firms listed in the Compustat Industrial Annual files between 1971 and 2011, this correlation is on average negative. Using data on U.S. nonfinancial firms between 1972 to 2006, Riddick and Whited (2009) find that the sensitivity of saving to cash flow is negative. 


\subsection{Fixed issuance costs}

We conclude this section with a discussion of the role of the scalability in $a$ in our model. Many firm variables scale up as the firm grows and becomes more productive and profitable. We have used this observation to motivate our assumption that the fixed refinancing cost is proportional to the firm's profitability $a$. As shown in Section 2, the ratio of cash holdings over profitability is the unique state variable for the firm's problem in this case and the firm's optimal policies can be fully characterized; see Proposition 1.

Suppose now that the fixed issuance cost is constant and does not depend on firm profitability $a$, so that the average equity issuance cost is lower for larger firms. Shareholders' optimization problem then involves a difficult mixed control and stopping problem with two state variables, cash reserves $m$ and profitability $a$. With a constant fixed cost $\phi$, liquidation should be optimal as profitability $a$ and firm value approach 0 . As profitability $a$ increases, the firm effectively outgrows the fixed issuance $\operatorname{cost} \phi$ and its optimal policy should converge to that of a firm with only proportional issuance costs. Our model gives the optimal policy with only proportional costs $(\phi=0$ and $p>1)$, in which the optimal issue size is $\bar{m}(a)=0$ and target cash reserves are $m^{*}(a)=c^{*} a$ for a constant $c^{*}$. Importantly, irrespective of the modeling of the fixed financing cost, we expect that constrained firms with high profitability will build up large liquid reserves to reduce the likelihood that a pure cash flow shock triggers liquidation despite the high value of their assets. This suggests that, in this case too, target cash holdings should be increasing in profitability, as established in Proposition 1.

\section{Risk management}

In our model, financing frictions imply that firm value is concave and that management may wish to reduce risk by engaging in hedging strategies. In addition, because firm cash flows are subject to permanent and transitory shocks that have different effects on the volatility of scaled cash holdings, the management of these two sources of risk may imply substantially different hedging strategies. To investigate these issues, we assume that the firm manages its risk exposure using derivatives such as futures contracts as in Bolton, Chen, and Wang (2011) 
and Hugonnier, Malamud, and Morellec (2015). Notably, we consider futures contracts with price $Y_{t}$ governed by:

$$
d Y_{t}=\sigma_{Y} Y_{t} d Z_{t}
$$

where $\sigma_{Y}$ is a positive constant and $Z=\left(Z_{t}\right)_{t \geq 0}$ is a standard Brownian motion.

We denote by $h_{t}$ the firm's position in the futures contracts (measured in dollar). The dynamics of cash reserves with futures hedging are then given by:

$$
d M_{t}=(r-\lambda) M_{t} d t+d X_{t}+\frac{d E_{t}}{p}-d \Phi_{t}-d L_{t}+h_{t} \sigma_{Y} d Z_{t}
$$

Equation (32) shows that an important aspect of hedging with derivatives contracts is that it produces additional short-term cash flows $\left(h_{t} \sigma_{Y} d Z_{t}\right)$. Asset substitution does not have this feature. As a result, cash holdings and financing frictions will be important in determining whether firms manage their risks by using derivatives contracts or by changing asset exposure to permanent and transitory shocks.

\subsection{Risk management with derivatives}

We start our analysis by considering an environment in which hedging is costless (or unconstrained) in that there are no requirements of maintaining a margin account. Suppose first that the firm manages only transitory shocks using futures contracts (by the firm's choice or because only futures correlated with transitory shocks are available). Let $\chi_{T}$ denote the correlation between $Z_{t}$ and $W_{t}^{T}\left(Z_{t}\right.$ and $W_{t}^{P}$ are uncorrelated here). Using the same steps as above, it is immediate to show that the value of an active firm that engages in risk management satisfies in the earnings retention region:

$$
\begin{aligned}
r V(a, m) \quad & \left.=\mu a V_{a}(a, m)+(\alpha a+(r-\lambda) m) V_{m}(a, m)\right) \\
& +\frac{1}{2} a^{2}\left(\sigma_{A}^{2} V_{a a}(a, m)+2 \rho \sigma_{A} \sigma_{X} V_{a m}(a, m)+\sigma_{X}^{2} V_{m m}(a, m)\right) \\
& +\max _{h} \frac{1}{2}\left\{h^{2} \sigma_{Y}^{2} V_{m m}(a, m)+2 \chi_{T} \sqrt{1-\rho^{2}} h \sigma_{Y} \sigma_{X} a V_{m m}(a, m)\right\} .
\end{aligned}
$$


Defining shareholders' scaled value function as $F(c) \equiv \frac{V(a, m)}{a}$, we have that $F$ satisfies:

$$
\begin{aligned}
&(r-\mu) F(c)=(\alpha+c(r-\lambda-\mu) \quad F^{\prime}(c)+\frac{1}{2}\left(\sigma_{A}^{2} c^{2}-2 \rho \sigma_{A} \sigma_{X} c+\sigma_{X}^{2}\right) F^{\prime \prime}(c) \\
&+\max _{g}\left\{\frac{1}{2}\left(\sigma_{Y}^{2} g^{2}+2 \chi_{T} \sigma_{X} \sigma_{Y} \sqrt{1-\rho^{2}} g\right) F^{\prime \prime}(c)\right\},
\end{aligned}
$$

where $g=\frac{h}{a}$ is the hedge ratio. ${ }^{14}$ The first-order condition associated with (34) yields

$$
g_{T}^{*}=-\left(\frac{\chi_{T}}{\sigma_{Y}}\right) \sigma_{X} \sqrt{1-\rho^{2}}
$$

Substituting (35) in (34) then yields

$$
(r-\mu) F(c)=(\alpha+c(r-\lambda-\mu)) F^{\prime}(c)+\frac{1}{2} \Sigma(c) F^{\prime \prime}(c),
$$

with $\Sigma(c)=\sigma_{A}^{2} c^{2}-2 \rho \sigma_{A} \sigma_{X} c+\sigma_{X}^{2}-\chi_{T}^{2} \sigma_{X}^{2}\left(1-\rho^{2}\right)>0$ for $\rho \in[-1,1)$, which implies that $F$ is concave and, in turn, that equation (35) gives the optimal hedge ratio.

Suppose next that the firm manages only its exposure to permanent shocks. Let $\chi_{P}$ denote the correlation with between $Z_{t}$ and $W_{t}^{P}\left(Z_{t}\right.$ and $W_{t}^{T}$ are uncorrelated here). In this case, firm value satisfies in the earnings retention region:

$$
\begin{aligned}
r V(a, m) \quad & \left.=\mu a V_{a}(a, m)+(\alpha a+(r-\lambda) m) V_{m}(a, m)\right) \\
& +\frac{1}{2} a^{2}\left(\sigma_{A}^{2} V_{a a}(a, m)+2 \rho \sigma_{A} \sigma_{X} V_{a m}(a, m)+\sigma_{X}^{2} V_{m m}(a, m)\right) \\
& +\max _{h} \frac{1}{2}\left\{h^{2} \sigma_{Y}^{2} V_{m m}(a, m)+2 \chi_{P} \rho h \sigma_{Y} \sigma_{X} a V_{m m}(a, m)+2 \chi_{P} h \sigma_{Y} \sigma_{A} a V_{a m}(a, m)\right\} .
\end{aligned}
$$

This in turn implies that the scaled value function $F(c)$ satisfies

$$
\begin{aligned}
(r-\mu) F(c)=(\alpha & +c(r-\lambda-\mu)) F^{\prime}(c)+\frac{1}{2}\left(\sigma_{A}^{2} c^{2}-2 \rho \sigma_{A} \sigma_{X} c+\sigma_{X}^{2}\right) F^{\prime \prime}(c) \\
& +\max _{g}\left\{\frac{1}{2}\left(\sigma_{Y}^{2} g^{2}+2 \sigma_{X} \sigma_{Y} \chi_{P} \rho g-2 c \sigma_{A} \sigma_{Y} \chi_{P} g\right) F^{\prime \prime}(c)\right\} .
\end{aligned}
$$

\footnotetext{
${ }^{14}$ The firm in our model hedges cash flows with expected profitability $A_{t}$ so this denominator of a hedge ratio follows the usual practice in risk management literature (see e.g. Tufano (1996))
} 
The first-order condition with respect to the hedge ratio yields:

$$
g_{P}^{*}=-\left(\frac{\chi_{T}}{\sigma_{Y}}\right)\left(\rho \sigma_{X}-c \sigma_{A}\right) \text {. }
$$

Substituting the expression for $g_{P}^{*}$ in (38) yields

$$
(r-\mu) F(c)=(\alpha+c(r-\lambda-\mu)) F^{\prime}(c)+\frac{1}{2} \Sigma(c) F^{\prime \prime}(c)
$$

where $\Sigma(c)=\sigma_{A}^{2} c^{2}-2 \rho \sigma_{A} \sigma_{X} c+\sigma_{X}^{2}-\chi_{P}^{2}\left(\sigma_{A} c-\sigma_{X} \rho\right)^{2}>0$ for $\rho \in[-1,1)$, which implies that $F$ is concave and, in turn, that equation (39) defines the optimal dynamic hedging.

Equations (35) and (39) show that the signs of the hedge ratios are opposite to the signs of the volatilities associated to transitory and permanent shocks in the dynamics of scaled cash holdings (see equation (16)). The optimal hedging policy with respect to transitory shocks is expected and known; see for example Bolton, Chen, and Wang (2011). The hedge ratio with respect to transitory shocks is constant. The firm takes a position in future contracts that is opposite to its core risk exposure and eliminates all the correlated risk.

The optimal hedging policy with respect to permanent shocks is new and more surprising. Substituting the expression for $h_{P}^{*} \equiv a g_{P}^{*}$ in (32) shows that optimal hedging of permanent shocks adds two terms to the dynamics of cash reserves. The first one, $-\chi_{P} \rho \sigma_{X} A_{t} d Z_{t}$, serves to remove the correlated risk from firm cash flows. The second one, $\chi_{P} \sigma_{A} M_{t} d Z_{t}$, is specific to hedging of permanent shocks and has a double impact. First, it increases the volatility of cash flows. Second, it increases the correlation of cash flow shocks. In other words, the two opposing effects of a positive permanent shock discussed in section 2 are again at work. Consequently, risk management of permanent shocks may imply long or short positions in derivatives depending on the level of the cash reserve $c=\frac{m}{a}$ relative to $\rho \frac{\sigma_{X}}{\sigma_{A}}$. Specifically, when $\chi_{P}>0$ the short position dominates for $c<\rho \frac{\sigma_{X}}{\sigma_{A}}$ while the long position dominates for $c>\rho \frac{\sigma_{X}}{\sigma_{A}}$. The long position dominates in particular if the correlation between short-term and permanent cash flow shocks $\rho$ is low and if the firm is relatively cash rich (high $c$ ). Therefore, despite the concavity of the scaled value function, risk management of permanent shocks with derivatives may imply a position that is not opposed but aligned with the exposure. This is 
due to the fact that hedging increases both cash flow volatility and the correlation of cash flow shocks. As discussed above, the firm benefits from the correlation between shocks, i.e. from generating liquidity when long-term prospects improve. ${ }^{15}$

In summary, hedging policies with respect to transitory and permanent shocks are markedly different. The hedge ratio with respect to transitory shocks is constant while the hedge ratio with respect to permanent shocks is linear in scaled cash holdings $c$. Furthermore, the signs of the optimal hedge ratios $g_{T}^{*}$ and $g_{P}^{*}$ can be opposite. Our analysis has focused for clarity on hedging positions with respect to one source of risk. If the futures price is correlated with both $W^{T}$ and $W^{P}$, as is likely to be the case, the optimal hedge ratio is simply $g^{*}=g_{T}^{*}+g_{P}^{*}$. Consider for example a primary commodity producer. The literature stresses that commodity prices are subject to transitory and permanent shocks and emphasizes the importance of precautionary savings and hedging in the primary commodity producing sector (see for instance Reinhart and Wickham (1994)). Our study suggests that hedging policies in commodities markets should vary with the relative importance of firms' exposure to permanent and transitory shocks, i.e. with the nature of the shocks affecting these commodity prices.

How does hedging affect optimal policies? To answer this question, we solve our model with and without hedging and compare optimal policies. If perfect hedging is possible, in that $\chi_{T}=\chi_{P}=1$, then the firm can decrease target cash holdings by as much as $89.1 \%$ with hedging of transitory shocks and by $8.5 \%$ with hedging of permanent shocks. The optimal size of equity issues decreases by $85.2 \%$ with hedging of transitory shocks and by $3.2 \%$ with hedging of permanent risk. That is, if the availability of futures contracts is symmetric for the two types of shocks, hedging of transitory shocks has a more significant effect on other firm policies than hedging of permanent shocks. If futures are less perfectly correlated with cash flows, the effects are naturally smaller but the pattern remains the same. Taking more realistic correlations of $\chi_{T}=\chi_{P}=0.7$, target cash holdings decrease by $34.2 \%$ (resp. $4.2 \%$ ) with hedging of transitory (resp. permanent) shocks. Equity issuance size decreases now by $28.7 \%$ (resp. 1.5\%) with hedging of transitory (resp. permanent) shocks.

\footnotetext{
${ }^{15}$ The positive sign in $g_{P}^{*}$ stems from the positive sign of $V_{a m}=-\frac{c}{a} F^{\prime \prime}$ as opposed to the negative signs of $V_{a a}$ and $V_{m m}$. This positive sign implies that the marginal value of cash increases in profitability. Note also that it would be misleading to call the firm's risk management policy to permanent shocks as "speculation," since taking a position that is not contrary to the exposure actually reduces risk.
} 
Lastly, suppose that hedging positions are not unbounded but are instead constrained by the requirement of maintaining a margin account. Specifically, assume that the firm's net futures position cannot exceed the amount on the margin account by more than a factor $\pi$. Assuming that the margin account earns the same interest as the common cash account, all cash holdings can be moved to the margin account if needed, so that the marginaccount constraint is equivalent to limiting the futures position to a $\pi$ multiple of cash holdings, or $\left|h_{t}\right| \leq \pi M_{t}$. In terms of hedge ratio, the constraint can then be written as $\left|g_{t}\right| \leq \pi C_{t}$. In such environments, constrained firms (i.e. firms with low $c$ ) hedge less due to difficulties with meeting margin requirements, consistent with the evidence in Rampini, Sufi, and Viswanathan (2014) that collateral constraints play a major role in risk management.

\subsection{Hedging using derivatives versus asset substitution}

An alternative to risk management using derivatives is to change the firm's assets to achieve a different exposure to transitory or permanent shocks. This is a version of asset substitution. An important difference between asset substitution and hedging with derivatives is that the former does not generate cash flows. Whether risk management generates cash flows or not is not important in models with unconstrained financing (like Leland (1998)), but this is relevant in a model with financing frictions like ours (see also Mello and Parsons (2000)).

Suppose that the firm can manage costlessly its asset risk via unconstrained selection of volatilities of short-term or permanent shocks, $\sigma_{X}$ and $\sigma_{A}$. Consider first short-term shocks. The discussion below equation (25) suggests that the usual effect of $\sigma_{X}$ on (scaled) firm value is negative and so the optimal policy is to set $\sigma_{X}=0$. This shows that the outcome of derivative hedging and asset risk management are the same: The firm aims at removing all exposure to short-term shocks and the two methods are equivalent.

Consider next permanent shocks. Using (26), we have that the first-order derivative of firm value with respect to $\sigma_{A}$ is always negative if $\rho \leq 0$. In these instances, it is optimal to set $\sigma_{A}=0$. If instead $\rho>0$, the optimal exposure $\sigma_{A}$ to the permanent shock $W^{P}$ satisfies:

$$
\sigma_{A}=\rho \sigma_{X} / c
$$


Plugging the expression for $\sigma_{A}$ in the volatility of scaled cash holdings, we get a resulting volatility given by $\sigma_{X} \sqrt{1-\rho^{2}}$. Two observations are in order. First, the firm is willing to maintain a positive volatility of permanent shocks. In essence, this happens because volatility of scaled cash holding $c$ is not the lowest at $\sigma_{A}=0$ but when $\sigma_{A}$ is at a right proportion to $\sigma_{X}, \rho$, and $c$ such that (40) holds. Second, the optimal volatility of permanent shocks is large when $c$ is small. A high $\sigma_{A}$ contributes to the volatility of $c$ positively and directly by changing the volatility of permanent shocks, via $\sigma_{A}^{2} c^{2}$, and indirectly via the covariance term, $2 \rho \sigma_{A} \sigma_{X} c$. If $c$ is low, the direct volatility effect, being quadratic in $c$, is dwarfed by the covariance term. By selecting a high exposure to permanent shocks $\sigma_{A}$, the firm can benefit from the increased covariance with little cost of increased variance.

Managing permanent risk with either derivatives or asset substitution typically increases beneficial correlation at the cost of an increased volatility. The difference between derivatives and asset risk management is that the former manipulates short-term cash flow volatility and the latter affects long-term asset-profitability volatility. This implies that the two strategies have different incentives with varying $c$ for a financially constrained firm. For example, derivative hedging looses some of its potential when a firm is financially weaker, i.e. when $c$ is low. A firm with little cash, cannot afford to generate cash flow shocks to benefit from an increased covariance between cash flow shocks, as this would put it at risk of running out of cash quickly. By contrast, a distressed firm would have strong incentives to engage in asset substitution to increase $\sigma_{A}$. That is, we predict that if a firm was mostly exposed to permanent shocks, this firm should decrease its derivatives usage and potentially increase its asset risk as it approaches distress, i.e. as its liquid reserves decrease.

\section{Credit lines}

Another way for firms to manage their risks is to acquire financial flexibility via a credit line. Suppose that the firm has access to a credit line that allows it to borrow from creditors up to some collateral constraint. In our model, the value of the firm's assets at any time $t>0$ is given by $A_{t}$. It is thus natural to consider a constraint of the type $M_{t} \geq-\kappa A_{t}$ for some positive constant $\kappa$, as in Bolton, Chen, and Wang (2011). The logic behind this assumption 
is that the firm must be able to post collateral to secure a credit line. We may thus interpret $\kappa A_{t}$ as the firm's short-term debt capacity. For simplicity, we treat $\kappa$ as exogenous.

Introducing financial leverage and collateral constraints in the model implies an important additional effect of permanent shocks. Notably, a positive permanent shock increases the value of assets and therefore relaxes the collateral constraint, allowing the firm to cope with larger transitory shocks. This effect works in the opposite direction from the effect described in section 2 above, in which a permanent shock made the firm more constrained. ${ }^{16}$

Assuming that the firm pays a spread $\xi>0$ over the risk-free rate to access credit, it will optimally avoid using its credit line before exhausting internal funds. When running out of cash, the firm will first use its credit line and, as long as the spread $\xi$ is not too high, it will exhaust the credit line before raising equity. ${ }^{17}$ Since the collateral constraint scales with $A_{t}$, similar derivations as above show that when the credit line is the marginal source of financing (i.e. when $c<0$ ), the scaled value function $F(c)$ satisfies:

$$
(r-\mu) F(c)=(\alpha+c(r+\xi-\mu)) F^{\prime}(c)+\frac{1}{2}\left(\sigma_{A}^{2} c^{2}-2 \rho \sigma_{A} \sigma_{X} c+\sigma_{X}^{2}\right) F^{\prime \prime}(c),
$$

which is solved subject to

$$
F(-\kappa)=\max \left(\max _{c \in[-\kappa, \infty)}(F(c)-p(c+\kappa+\phi)) ; \frac{\omega \alpha}{r-\mu}-\kappa\right)
$$

when the firm exhausts the credit line. When refinancing at $c=-\kappa$ is optimal, scaled cash holdings after refinancing $\bar{c}_{L}$ are given by the solution to $F^{\prime}\left(\bar{c}_{L}\right)=p$. In the earnings

\footnotetext{
${ }^{16}$ Note that if in addition to this credit line the firm had some debt outstanding, a positive permanent shock would not only increase the firm's debt capacity via the credit line but also make the firm less levered. We thank an anonymous referee for making this point and encouraging us to write this section.

${ }^{17}$ To see why the firm always first relies on the credit line, assume for simplicity that there is no fixed cost of raising equity so that $\phi=0$. Given a sufficiently deep credit line, when is it optimal to issue equity? The firm issues equity only when $c \leq 0$ and at the optimal threshold $\underline{c}$, it holds that $F^{\prime}(\underline{c})=p$ and $F^{\prime \prime}(\underline{c})=0$. Suppose now that it is optimal to issue equity at $c=0$ rather than use the credit line so that $\underline{c}=0$. The above two conditions then imply $F(0)=p \alpha /(r-\mu)>F^{F B}(0)$, which cannot be. Another question that naturally arises is whether it is optimal for the firm to use all of its credit line before issuing equity. For any set of parameters, we can find a (non-positive) threshold $\underline{c}$ such that the firm optimally issues equity whenever $c<\underline{c}$ irrespective of the limit of the credit line. At the optimal $\underline{c}$, firm value satisfies value-matching and smooth-pasting conditions: $F(\underline{c})=F(\bar{c})-p(\bar{c}-\underline{c}+\phi)$ and $F^{\prime}(\underline{c})=p$, where we have assumed that $\phi>0$. If the level of indebtedness that triggers optimal equity issuance $(-\underline{c})$ exceeds the limit of the credit line $(\kappa)$, the firm uses all of its credit line before raising equity. Otherwise, it issues equity before exhausting the credit line. For the parameter values used in this section, we find that $-\underline{c}>\kappa$.
} 
Figure 4: Credit lines and cash flow correlation
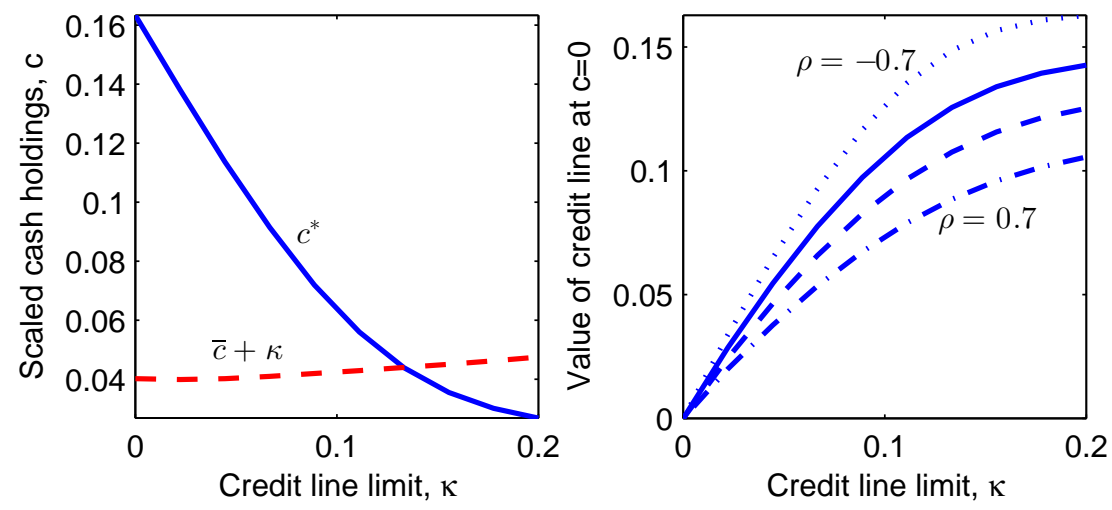

Notes. The left panel plots target cash holdings $c_{L}^{*}$ (solid curve) and the scaled issuance size $\bar{c}_{L}+\kappa$ (dashed curve) in the refinancing case. The right panel plots a change in firm value at $c=0$ for four values of the correlation between permanent and transitory shocks ( $\rho=0.7$ dashed-dotted, $\rho=0.21$ dashed, $\rho=-0.21$ solid, and $\rho=-0.7$ dotted). Parameter values are given in Table 1 .

retention region $\left(0, c_{L}^{*}\right)$, the scaled value function satisfies (18), which is solved subject to (20) and (21). Also, since cash flows are (piecewise) continuous, the scaled value function $F(c)$ is continuous and smooth everywhere, including at $c=0$, implying that $\lim _{c \downarrow 0} F(c)=$ $\lim _{c \uparrow 0} F(c)$, and $\lim _{c \downarrow 0} F^{\prime}(c)=\lim _{c \uparrow 0} F^{\prime}(c)$. Lastly, in the region $c \geq c_{L}^{*}$, the firm pays out any cash in excess of $c_{L}^{*}$ and we have $F(c)=F\left(c_{L}^{*}\right)+c-c_{L}^{*}$.

Figure 4 describes the effects of a credit line by varying $\kappa$ in an environment characterized by the same parameter values as in Table 1 and in which $\xi=1.5 \%$, consistent with Sufi (2009). The figure shows that an increase in the size of the credit line $\kappa$ leads to a significant decrease in the target level of cash holdings but has little effect on the optimal size of equity issues. Figure 4 also shows that a credit line increases firm value by reducing refinancing costs. Notably, even when the credit line is not drawn, an increase in the credit limit $\kappa$ may increase firm value by an amount close to that limit.

Interestingly, we also find that a firm with a credit line may respond differently to permanent shocks than a firm relying exclusively on cash reserves to absorb negative cash flow shocks. This is due to the fact that the marginal value of cash increases in $a$ if $c>0$, in 
that $V_{a m}=-\frac{c}{a} F^{\prime \prime}(c)>0$, but it decreases in $a$ if $c<0$, in that $V_{a m}=-\frac{c}{a} F^{\prime \prime}(c)<0 .{ }^{18}$ That is, cash-financed firms value additional cash more when asset productivity increases while credit-financed firms value additional cash more when productivity decreases. This in turn suggests that firms that benefit most from credit lines are those whose permanent and transitory cash flow shocks are negatively correlated. The right panel of Figure 4 presents an example in which we plot the benefit of a credit line (measured by the change in firm value at $c=0$ due to the credit line) for various values of $\rho$. The effects are large: a credit line of 0.2 is worth 0.163 when $\rho=-0.7$ while the same credit line is worth only 0.106 when $\rho=0.7$. Thus our model predicts that credit lines should be more prevalent in firms and industries in which permanent and transitory cash flow shocks are negatively correlated.

\section{Investing in financially-constrained firms}

Consider now the initial decision to invest in the firm. In the presence of transitory shocks and financing frictions, the firm finds it optimal to hold cash after investment. Thus, solving shareholders' problem entails finding both the optimal time to invest $\tau$ as well as the optimal initial level of cash reserves $m_{0}$. Denote the value of the investment opportunity by $G(a)$. Shareholders' optimization problem before investment can be written as:

$$
G(a)=\sup _{\tau, m_{0} \geq 0} \mathbb{E}_{a}\left[e^{-r \tau}\left(V\left(A_{\tau}, m_{0}\right)-p\left(I+m_{0}+\phi A_{\tau}\right)\right)\right]
$$

Following the literature on investment decisions under uncertainty (see Dixit and Pindyck (1994)), it is natural to conjecture that the optimal investment strategy is to invest when the value of the active firm exceeds the cost of investment by a sufficiently large margin. In models without financing frictions, this margin reflects the value of postponing investment until more information about asset productivity is available. In addition to this effect arising from the irreversibility of the investment decision, our model incorporates a second friction: Operating the asset may create temporary losses and financing these losses is costly.

Specifically, for any initial level of reserves, the investment policy takes a form of a barrier policy whereby the firm invests as soon as asset productivity reaches some endogenous upper

\footnotetext{
${ }^{18}$ The scaled value function is concave for all $c \in\left(\kappa, c^{*}\right)$ for the parameter values used in this section.
} 
barrier. Denote the optimal barrier by $a^{*}$. Investment is then undertaken the first time that $A_{t}$ is at or above $a^{*}$. For any investment time $\tau$, the optimal initial level of cash reserves $m_{0}$, if positive, must satisfy the first-order condition in problem (43). That is, we must have:

$$
V_{m}\left(A_{\tau}, m_{0}\right)=p .
$$

This is the same condition as the one used in equation (13) for optimal cash reserves after refinancing. Thus, the initial level of cash reserves, if positive, is given by $m_{0}=\bar{c} a^{*}$.

Since the firm does not deliver any cash flow before investment, standard arguments imply that the value of the investment opportunity $G(a)$ satisfies for any $a \in\left(0, a^{*}\right)$ :

$$
r G(a)=\mu a G^{\prime}(a)+\frac{1}{2} \sigma_{A}^{2} a^{2} G^{\prime \prime}(a) .
$$

At the investment threshold, the value of the option to invest $G(a)$ must equal the value of an active firm minus the cost of acquiring the assets and the costs of raising the initial cash. This requirement, together with $m_{0}=\bar{m}(a)=\bar{c} a$, yields the value-matching condition:

$$
G\left(a^{*}\right)=a^{*} F(\bar{c})-p I-p\left(\bar{c} a^{*}+\phi a^{*}\right) .
$$

Optimality of $a^{*}$ further requires that the slopes of the pre- and post-investment values are equal when $a=a^{*}$. That is, $G(a)$ satisfies the smooth-pasting condition:

$$
G^{\prime}\left(a^{*}\right)=F(\bar{c})-p(\bar{c}+\phi) .
$$

Solving shareholders' optimization problem yields the following result.

Proposition 3. The following holds:

1. Suppose that the costs of external finance are low, in that $F(0)>\omega \alpha /(r-\mu)$. In this case, the value of the option to invest is given by

$$
G(a)= \begin{cases}\left(\frac{a}{a^{*}}\right)^{\xi}\left(a^{*} F(0)-p I\right), & \forall a \in\left(0, a^{*}\right), \\ a F(0)-p I, & \forall a \geq a^{*},\end{cases}
$$


where the value-maximizing investment threshold satisfies

$$
a^{*}=\frac{\xi}{\xi-1} \frac{p I}{F(0)}
$$

with

$$
\xi=g\left(\sigma_{A}, \mu\right)+\sqrt{\left[g\left(\sigma_{A}, \mu\right)\right]^{2}+2 r / \sigma_{P}^{2}}>1
$$

where $g\left(\sigma_{A}, \mu\right)=\frac{1}{2 \sigma_{A}^{2}}\left(\sigma_{A}^{2}-2 \mu\right)$. Investment is undertaken the first time that $A_{t} \geq a^{*}$ and the firm's cash reserves at the time of investment are given by $m_{0}=\bar{c} a^{*}$.

2. Suppose that the costs of external finance are high, in that $F(0)=\omega \alpha /(r-\mu)$.

(a) If $\omega \alpha /(r-\mu)>p \phi$, the value of the option to invest is given by

$$
G(a)= \begin{cases}\left(\frac{a}{a^{*}}\right)^{\xi}\left(a^{*}(\omega \alpha /(r-\mu)-p \phi)-p I\right), & \forall a \in\left(0, a^{*}\right), \\ a(\omega \alpha /(r-\mu)-p \phi)-p I, & \forall a \geq a^{*},\end{cases}
$$

where the value-maximizing investment threshold satisfies

$$
a^{*}=\frac{\xi}{\xi-1} \frac{p I}{\omega \alpha /(r-\mu)-p \phi}
$$

and $\xi$ is defined in (50). Investment is undertaken the first time that $A_{t} \geq a^{*}$. No cash is raised in addition to I and it is optimal to liquidate right after investment.

(b) If $\omega \alpha /(r-\mu) \leq p \phi$, the firm never invests and $G(a)=0, \forall a>0$.

As in standard real options models, Proposition 3 shows that, the value of the option to invest is the product of two terms: The net present value of the project at the time of investment, given by $a^{*} F(0)-p I$ or $a^{*}(\omega \alpha /(r-\mu)-p \phi)-p I$, and the present value of $\$ 1$ to be obtained at the time of investment, given by $\left(\frac{a}{a^{*}}\right)^{\xi}$. When issuance costs are high, it is either optimal to liquidate right after investment or to refrain from investing altogether.

Focusing on the more interesting case in which the costs of external finance are low, one can note that when $p=1$ and the firm cash flows are not subject to transitory shocks 
Table 2: Financing constraints and investment delay

\begin{tabular}{lcc}
\hline Parameters & $\begin{array}{c}\text { Delay in investment } \\
\text { due to financing constraints } \\
\left(\text { as } \% \text { of } a_{F B}^{*}\right)\end{array}$ & $\begin{array}{c}\% \text { of the delay due to } \\
\text { at-investment } \\
\text { constraints }\end{array}$ \\
\hline 1. $\sigma_{X}=0.12, \lambda=0.02$ & $8.0 \%$ & $75.9 \%$ \\
2. $\sigma_{X}=0.15, \lambda=0.03$ & $9.6 \%$ & $63.7 \%$ \\
3. $\sigma_{X}=0.09, \lambda=0.01$ & $6.8 \%$ & $88.7 \%$ \\
\hline
\end{tabular}

Notes. Table 2 presents the quantitative effects of financing constraints on the investment threshold and their decomposition. Input parameter values are given in Table 1.

$\left(\sigma_{X}=0\right)$, the optimal investment threshold becomes

$$
a_{F B}^{*}=\frac{\xi}{\xi-1} \frac{I}{F^{F B}}
$$

where $F^{F B}=\frac{V^{F B}(a)}{a}=\frac{\alpha}{r-\mu}$. Equation (53) recovers the well-known investment threshold of real options models (see e.g. Dixit and Pindyck (1994)). Except for two special cases $(p=1$ and $\sigma_{X}=0$ or $p=1$ and $\left.\phi=0\right), F(0)$ is strictly lower than $F^{F B}$, so that the investment threshold of Proposition 3 is strictly higher than the standard real options threshold. Our results are therefore very different from those in prior studies, such as Boyle and Guthrie (2003), in which firms face financing constraints when seeking to invest in new projects. In such models, potential future financing constraints feed back in current policy choices and encourage early investment. Our analysis highlights another way by which financing frictions can distort investment behavior: The threat of future cash shortfalls increases future financing costs and reduces the value of the asset underlying the firm's growth option, thereby leading to late exercise of the investment opportunity.

More generally, financing frictions have two separate effects on the timing of investment in our model. First, they increase the cost of investment, thereby delaying investment. Second, they reduce the value of an active firm, further delaying investment. Table 2 shows how these two effects vary with input parameter values. In our base case environment, Case 1 in 
the table, financing frictions increase the investment threshold by $8.0 \%$ and three quarters of the delay in investment is due to financing frictions at the time of investment. As shown by the table, a firm with a higher volatility of transitory cash flow shocks $\left(\sigma_{X}=0.15\right)$ and higher costs of holding cash $(\lambda=0.03)$ optimally invests at yet a higher threshold relative the first-best, with more than one third of the delay coming from the post-investment financing frictions. A firm with a relatively low cash flow volatility and low costs of holding cash (Case 3 in the table) invests at a lower threshold, but still much above the first-best threshold. In this case, the bulk of the delay is due to financing frictions at investment.

\section{Conclusion}

Our paper contributes to the literature on the effects of financing frictions on corporate policies. Previous studies have focused on the uncertainty of cash flows as one of the important determinants of liquidity and risk management policies. We demonstrate that these policies can be better understood as arising from two separate types of shocks: permanent and transitory shocks to cash flows. The main distinction between permanent and transitory shocks is that permanent shocks affect not only a firm's immediate productivity and cash flows but also its future productivity and cash flows. By contrast, while transitory shocks affect immediate cash flows, they are uninformative about future expected profitability. To illustrate the differential effects of these two types of shocks on corporate policies, we construct a dynamic model of a firm facing financing frictions and subject to transitory and permanent cash flow shocks. Using this model, we show that combining permanent and transitory shocks helps explain corporate behavior and produces several novel implications about the level of cash savings and optimal financing and risk management policies.

In our model, both permanent and transitory cash flow shocks induce the firm to save. Optimal cash savings decrease with the correlation between permanent and transitory shocks. This correlation is also a key driver of the cash-flow sensitivity of cash, which can be positive or negative. In addition, when firms access capital markets to raise funds, the size of equity issues is not constant as in prior models, but reflects the level and dynamics of permanent shocks. We also show that introducing permanent shocks in models with financing frictions 
leads to richer risk management policies, that depend on the nature of the cash flow shocks. In particular, we show that if the firm's risk and futures prices are positively correlated, then hedging transitory shocks involves a short futures position while hedging permanent shocks may require a long futures position. We also show that managing risk either by derivatives or by directly selecting the riskiness of assets via asset substitution leads to the same outcome if the risk is due to transitory shocks. However, derivatives and asset substitution are not equivalent when managing permanent shocks. Lastly, because the correlation between permanent and transitory cash flow shocks reduces firm risk, we also find that the firms that benefit most from credit lines are those in which these shocks are negatively correlated. 


\section{Appendix}

\section{A. Proof of Proposition 1}

The proof goes through three steps. Step 1 shows that problem (7) can be re-written as a one-dimensional control problem. Step two solves the variational system (18), (19), (22). Step 3 shows that the solution to (18), (19), (22) coincides with the solution of the onedimensional control problem and derives the optimal dividend and issuance policies. To avoid confusion, throughout the proof, $V^{*}$ and $F^{*}$ denote the value functions of the control problems while $V$ and $F$ denote the solution to the variational systems.

Step 1. Let $\tilde{\mathbb{P}}$ be the probability defined by

$$
\left(\frac{d \mathbb{P}}{d \tilde{\mathbb{P}}}\right)_{\mid \mathcal{F}_{t}}=Z_{t} \equiv \exp \left\{-\frac{1}{2} \sigma_{A}^{2} t+\sigma_{A} W_{t}^{P}\right\}, \quad \forall t \geq 0
$$

on $(\Omega, \mathcal{F})$. By Girsanov's Theorem, $\left(\tilde{W}_{t}^{P}, W_{t}^{T}\right)_{t \geq 0}$ with $\tilde{W}_{t}^{P}=-\sigma_{A} t+W_{t}^{P}$, is a bi-dimensional Brownian motion under the probability $\widetilde{\mathbb{P}}$. We have:

Proposition 4. The value function $V^{*}$ of problem (7) satisfies

$$
V^{*}(a, m)=a F^{*}\left(\frac{m}{a}\right) .
$$

The function $F^{*}$ is defined on $[0, \infty)$ by

$$
F^{*}(c)=\sup _{\left(\left(\tau_{n}\right)_{n \geq 1},\left(e_{n}\right)_{n \geq 1}, L\right) \in \mathcal{A}} f\left(c ;\left(\tau_{n}\right)_{n \geq 1},\left(e_{n}\right)_{n \geq 1}, L\right),
$$

with

$$
f\left(c ;\left(\tau_{n}\right)_{n \geq 1},\left(e_{n}\right)_{n \geq 1}, L\right)=\mathbb{E}_{c}^{\tilde{\mathbb{P}}}\left[\int_{0}^{\tau_{0}} e^{-(r-\mu) t}\left(d \tilde{L}_{t}-d \tilde{E}_{t}\right)+e^{-(r-\mu) \tau_{0}} \frac{\omega \alpha}{r-\mu}\right]
$$

and $C_{0}=c$ with

$$
d C_{t}=\left(\alpha+C_{t}(r-\lambda-\mu)\right) d t+\sqrt{\sigma_{A}^{2} C_{t}^{2}-2 \rho \sigma_{X} \sigma_{A} C_{t}+\sigma_{X}^{2}} d W_{t}^{C}+\frac{d \tilde{E}_{t}}{p}-d \tilde{\Phi}_{t}-d \tilde{L}_{t}
$$

where $W^{C}=\left(W_{t}^{C}\right)_{t \geq 0}$ is a standard Brownian motion under $\tilde{\mathbb{P}}$,

$$
\begin{aligned}
\tilde{\Phi}_{t} & =\sum_{n \geq 1} \phi \mathbb{1}_{\left\{\tau_{n} \leq t\right\}}, \\
\tilde{E}_{t} & =\sum_{n \geq 1} \tilde{e}_{n} \mathbb{1}_{\left\{\tau_{n}<t\right\}} \text { with } \tilde{e}_{n}=e_{n} A_{\tau_{n}}, \\
\tilde{L}_{t} & =\int_{0}^{t} \frac{1}{A_{s}} d L_{s}
\end{aligned}
$$


and the liquidation time $\tau_{0}$ is defined by

$$
\tau_{0}=\inf \left\{t \geq 0 \mid C_{t}=0\right\} .
$$

Proof of Proposition 4. Applying Itô's formula to $\left(e^{-r\left(t \wedge \tau_{0}\right)} M_{t \wedge \tau_{0}}\right)_{t \geq 0}$ and letting $t$ go to $\infty$ yields

$\mathbb{E}\left[\int_{0}^{\tau_{0}} e^{-r t}\left(d L_{t}-d E_{t}\right)\right]=m+\mathbb{E}\left[\int_{0}^{\tau_{0}} e^{-r t}\left(-\lambda M_{t}+\alpha A_{t}\right) d t\right]-\mathbb{E}\left[\int_{0}^{\tau_{0}} e^{-r t}\left(\frac{p-1}{p} d E_{t}+d \Phi_{t}\right)\right]$,

which we re-write under the form

$$
\begin{aligned}
\frac{1}{a} \mathbb{E}\left[\int_{0}^{\tau_{0}} e^{-r t}\left(d L_{t}-d E_{t}\right)\right]= & \frac{m}{a}+\mathbb{E}\left[\int_{0}^{\tau_{0}} e^{-(r-\mu) t} Z_{t}\left(-\lambda \frac{M_{t}}{A_{t}}+\alpha\right) d t\right] \\
& -\mathbb{E}\left[\int_{0}^{\tau_{0}} e^{-(r-\mu) t} Z_{t}\left(\frac{p-1}{p} \frac{d E_{t}}{A_{t}}+\frac{d \Phi_{t}}{A_{t}}\right)\right] .
\end{aligned}
$$

The change of probability measure (A1) yields

$$
\begin{aligned}
\frac{1}{a} \mathbb{E}\left[\int_{0}^{\tau_{0}} e^{-r t}\left(d L_{t}-d E_{t}\right)\right]= & \frac{m}{a}+\mathbb{E}^{\tilde{\mathbb{P}}}\left[\int_{0}^{\tau_{0}} e^{-(r-\mu) t}\left(-\lambda \frac{M_{t}}{A_{t}}+\alpha\right) d t\right] \\
& -\mathbb{E}^{\tilde{\mathbb{P}}}\left[\int_{0}^{\tau_{0}} e^{-(r-\mu) t}\left(\frac{p-1}{p} \frac{d E_{t}}{A_{t}}+\frac{d \Phi_{t}}{A_{t}}\right)\right] .
\end{aligned}
$$

Then, applying Itô's formula to $\left(\frac{M_{t}}{A_{t}}\right)_{t \geq 0}$ yields

$$
\begin{aligned}
\frac{M_{0}}{A_{0}}=\frac{m}{a}, \quad d\left(\frac{M_{t}}{A_{t}}\right)= & \left(\alpha+\frac{M_{t}}{A_{t}}(r-\lambda-\mu)\right) d t+\left(\sigma_{X} \rho-\frac{M_{t}}{A_{t}} \sigma_{A}\right) d \tilde{W}_{t}^{P} \\
& +\sigma_{X} \sqrt{1-\rho^{2}} d W_{t}^{T}+\frac{1}{A_{t}}\left(\frac{d E_{t}}{p}-d \Phi_{t}-d L_{t}\right),
\end{aligned}
$$

or equivalently,

$$
\begin{aligned}
\frac{M_{0}}{A_{0}}=\frac{m}{a}, \quad d\left(\frac{M_{t}}{A_{t}}\right)= & \left(\alpha+\frac{M_{t}}{A_{t}}(r-\lambda-\mu)\right) d t+\sqrt{\sigma_{A}^{2}\left(\frac{M_{t}}{A_{t}}\right)^{2}-2 \rho \sigma_{X} \sigma_{A} \frac{M_{t}}{A_{t}}+\sigma_{X}^{2}} d W_{t}^{C} \\
& +\frac{1}{A_{t}}\left(\frac{d E_{t}}{p}-d L_{t}\right)-d \tilde{\Phi}_{t},
\end{aligned}
$$

where $\left(W_{t}^{C}\right)_{t \geq 0}$ is a Brownian motion under $\tilde{\mathbb{P}}$. Applying Itô's formula to $\left(e^{-r\left(t \wedge \tau_{0}\right)} \frac{M_{t \wedge \tau_{0}}}{A_{t \wedge \tau_{0}}}\right)_{t \geq 0}$, letting $t$ go to $\infty$, and rearranging terms, we get

$$
\begin{aligned}
\mathbb{E}^{\tilde{\mathbb{P}}}\left[\int_{0}^{\tau_{0}} e^{-(r-\mu) t} \frac{1}{A_{t}}\left(d L_{t}-d E_{t}\right)\right]= & \frac{m}{a}+\mathbb{E}^{\tilde{\mathbb{P}}}\left[\int_{0}^{\tau_{0}} e^{-(r-\mu) t}\left(-\lambda \frac{M_{t}}{A_{t}}+\alpha\right) d t\right] \\
& -\mathbb{E}^{\tilde{\mathbb{P}}}\left[\int_{0}^{\tau_{0}} e^{-(r-\mu) t}\left(\frac{p-1}{p} \frac{d E_{t}}{A_{t}}+d \tilde{\Phi}_{t}\right)\right] .
\end{aligned}
$$


Noting that $\mathbb{E}\left[e^{-r \tau_{0}} \frac{\omega \alpha}{r-\mu} A_{\tau_{0}}\right]=a \mathbb{E}^{\tilde{\mathbb{P}}}\left[\frac{\omega \alpha}{r-\mu} e^{-(r-\mu) \tau_{0}}\right]$, we deduce then from (A10)

$\mathbb{E}\left[\int_{0}^{\tau_{0}} e^{-r t}\left(d L_{t}-d E_{t}\right)+e^{-r \tau_{0}} \frac{\omega \alpha A_{\tau_{0}}}{r-\mu}\right]=a \mathbb{E}^{\tilde{\mathbb{P}}}\left[\int_{0}^{\tau_{0}} e^{-(r-\mu) t} \frac{1}{A_{t}}\left(d L_{t}-d E_{t}\right)+e^{-(r-\mu) \tau_{0}} \frac{\omega \alpha}{r-\mu}\right]$.

To conclude the proof, note that problem

$$
\sup _{\left(\left(\tau_{n}\right)_{n \geq 1},\left(e_{n}\right)_{n \geq 1}, L\right) \in \mathcal{A}} \mathbb{E}^{\tilde{\mathbb{P}}}\left[\int_{0}^{\tau_{0}} e^{-(r-\mu) t} \frac{1}{A_{t}}\left(d L_{t}-d E_{t}\right)+e^{-(r-\mu) \tau_{0}} \frac{\omega \alpha}{r-\mu}\right],
$$

where the admissible policies $\left(\tau_{n}\right)_{n \geq 1},\left(e_{n}\right)_{n \geq 1}, L$ are related by

$$
\begin{aligned}
C_{0}=c, \quad d C_{t}= & \left(\alpha+C_{t}(r-\lambda-\mu)\right) d t+\sqrt{\sigma_{A}^{2} C_{t}^{2}-2 \rho \sigma_{X} \sigma_{A} C_{t}+\sigma_{X}^{2}} d W_{t}^{C} \\
& +\frac{1}{A_{t}}\left(\frac{d \tilde{E}_{t}}{p}-d \tilde{L}_{t}\right)-d \Phi_{t},
\end{aligned}
$$

together with (A7), (A8) is equivalent to problem (A3)-(A8).

The two next steps solve problem (A3). To this end, we solve first the variational system (18), (19), (22) (step 2). Then, we show that its solution coincides with the solution of problem (A3) (step 3).

Step 2 The following holds.

Proposition 5. There exists a unique solution $\left(F, c^{*}\right)$ to the variational system (18), (19), (22) that is concave and twice continuously differentiable over $(0, \infty)$.

The proof mimics the proof of Proposition A1 in Décamps, Mariotti, Rochet and Villeneuve (DMRV) (2011). The arguments must be slightly adapted because, in the ordinary differential equation (18), the drift $(\alpha+c(r-\lambda-\mu))$ can take negative values and $\Sigma(c) \equiv \sigma_{A}^{2} c^{2}-2 \rho \sigma_{X} \sigma_{A} c+\sigma_{X}^{2}$ is non-constant. For completness, we develop below the main steps of the proof with a particular focus on the arguments that require a slight adaptation. We refer to DMRV (2011) for more details.

Proof of Proposition 5: We start by considering the family of ordinary differential equations parametrized by $c_{1}>0$,

$$
\begin{array}{r}
-(r-\mu) F(c)+(\alpha+c(r-\lambda-\mu)) F^{\prime}(c)+\frac{1}{2}\left(\sigma_{A}^{2} c^{2}-2 \rho \sigma_{X} \sigma_{A} c+\sigma_{X}^{2}\right) F^{\prime \prime}(c)=0 \\
0<c<c_{1} \\
F^{\prime}\left(c_{1}\right)=1 \\
F^{\prime \prime}\left(c_{1}\right)=0 .
\end{array}
$$

Because $\rho \in[-1,1), \Sigma(c) \equiv \sigma_{A}^{2} c^{2}-2 \rho \sigma_{X} \sigma_{A} c+\sigma_{X}^{2}>0$ and (A12)-(A14) admits a unique solution $F_{c_{1}}$ over $\left[0, c_{1}\right]$ for any $c_{1}>0$. The next lemma establishes the monotonicity and 
concavity of $F_{c_{1}}$.

Lemma 1. The following holds:

(i) If $0<\lambda \leq r-\mu$ then, for any $c_{1}>0, F_{c_{1}}^{\prime}>1$ and $F_{c_{1}}^{\prime \prime}<0$ over $\left[0, c_{1}\right)$.

(ii) If $\lambda>r-\mu$ then, for any $0<c_{1}<\frac{\alpha}{\lambda+\mu-r}, F_{c_{1}}^{\prime}>1$ and $F_{c_{1}}^{\prime \prime}<0$ over $\left[0, c_{1}\right)$.

Proof of Lemma 1: Differentiating (A12) yields $\frac{1}{2} \Sigma\left(c_{1}\right) F_{c_{1}}^{\prime \prime \prime}\left(c_{1}\right)-\lambda F_{c_{1}}^{\prime}\left(c_{1}\right)=0$, which implies $F_{c_{1}}^{\prime \prime \prime}\left(c_{1}\right)>0$ because $\lambda>0$. Since $F_{c_{1}}^{\prime \prime}\left(c_{1}\right)=0$ and $F_{c_{1}}^{\prime}\left(c_{1}\right)=1$, it follows that $F_{c_{1}}^{\prime \prime}<0$ and thus $F_{c_{1}}^{\prime}>1$ over some interval $\left(c_{1}-\varepsilon, c_{1}\right)$ where $\varepsilon>0$. Now, suppose by way of contradiction that $F_{c_{1}}^{\prime}(c) \leq 1$ for some $c \in\left[0, c_{1}-\varepsilon\right]$, and let $\tilde{c}=\sup \left\{c \in\left[0, c_{1}-\varepsilon\right] \mid F_{c_{1}}^{\prime}(c) \leq 1\right\}<c_{1}$. Then, $F_{c_{1}}^{\prime}(\tilde{c})=1$ and $F_{c_{1}}^{\prime}>1$ over $\left(\tilde{c}, c_{1}\right)$, so that $F_{c_{1}}\left(c_{1}\right)-F_{c_{1}}(c)>c_{1}-c$ for all $c \in\left(\tilde{c}, c_{1}\right)$. Since $F_{c_{1}}\left(c_{1}\right)=\frac{\alpha}{r-\mu}+\frac{r-\lambda-\mu}{r-\mu} c_{1}$, this implies that for any such $c$,

$$
\begin{aligned}
F_{c_{1}}^{\prime \prime}(c) & =\frac{2}{\Sigma(c)}\left\{(r-\mu) F_{c_{1}}(c)-(\alpha+c(r-\lambda-\mu)) F_{c_{1}}^{\prime}(c)\right\} \\
& <\frac{2}{\Sigma(c)}\left\{(r-\mu)\left(c-c_{1}+F_{c_{1}}\left(c_{1}\right)\right)-(\alpha+(r-\lambda-\mu) c)\right\} \\
& =\frac{2}{\Sigma(c)} \lambda\left(c-c_{1}\right) \\
& <0 .
\end{aligned}
$$

To get (A15), remark that, by assumption, in each case (i) and (ii), we have $\alpha+(r-\lambda-\mu) c>0$ for any $c \in\left(\tilde{c}, c_{1}\right)$. To conclude, note that (A16) contradicts the fact that $F_{c_{1}}^{\prime}(\tilde{c})=F_{c_{1}}^{\prime}\left(c_{1}\right)=$ 1. Therefore $F_{c_{1}}^{\prime}>1$ over $\left[0, c_{1}\right)$, from which it follows that $F_{c_{1}}^{\prime \prime}<0$ over $\left[0, c_{1}\right)$.

If there exists a solution $F$ to (18), (19), (22) that is twice continuously differentiable over $(0, \infty)$, then, by construction, $F$ must coincide over $\left[0, c_{1}\right]$ with some $F_{c_{1}}$, for an appropraite choice of $c_{1}$. This choice is dictated by the boundary condition (22) that $F$ must satisfy at zero. The next lemma studies the behavior of $F_{c_{1}}$ and $F_{c_{1}}^{\prime}$ at zero as $c_{1}$ varies.

Lemma 2. In each of the two cases of Lemma $1, F_{c_{1}}(0)$ is a strictly decreasing and concave function of $c_{1}$, whereas $F_{c_{1}}^{\prime}(0)$ is a strictly increasing and convex function of $c_{1}$.

Proof of Lemma 2: consider $H_{0}$ and $H_{1}$ the solutions to ODE

$$
-(r-\mu) H(c)+(\alpha+c(r-\lambda-\mu)) H^{\prime}(c)+\frac{1}{2}\left(\sigma_{A}^{2} c^{2}-2 \rho \sigma_{X} \sigma_{A} c+\sigma_{X}^{2}\right) H^{\prime \prime}(c)=0
$$

over $[0, \infty)$ characterized by the initial conditions $H_{0}(0)=1, H_{0}^{\prime}(0)=0, H_{1}(0)=0$, and $H_{1}^{\prime}(0)=1$. $H_{0}^{\prime}$ and $H_{1}^{\prime}$ are strictly positive over $(0, \infty)$. The Wronskian $W_{H_{0} H_{1}} \equiv H_{0} H_{1}^{\prime}-$ $H_{1} H_{0}^{\prime}$ of $H_{0}$ and $H_{1}$ satisfies $W_{H_{0} H_{1}}(0)=1$ and

$$
W_{H_{0} H_{1}}^{\prime}(c)=-\frac{2}{\Sigma^{2}(c)}(\alpha+c(r-\lambda-\mu)) W_{H_{0} H_{1}}
$$


so that $W_{H_{0} H_{1}}>0$ which implies that for each $c_{1}>0, F_{c_{1}}=F_{c_{1}}(0) H_{0}+F_{c_{1}}^{\prime}(0) H_{1}$ over $\left[0, c_{1}\right]$. Using the boundary condition $F_{c_{1}}\left(c_{1}\right)=\frac{\alpha+c_{1}(r-\lambda-\mu)}{r-\mu}$ and $F_{c_{1}}^{\prime}\left(c_{1}\right)=1$, we obtain that

$$
\begin{aligned}
\frac{d F_{c_{1}}(0)}{d c_{1}} & =-\frac{1}{W_{H_{0} H_{1}}\left(c_{1}\right)} \frac{\lambda}{r-\mu} H_{1}^{\prime}\left(c_{1}\right)<0 \\
\frac{d^{2} F_{c_{1}}(0)}{d^{2} c_{1}} & =-\frac{1}{W_{H_{0} H_{1}}\left(c_{1}\right)} \frac{2 \lambda}{\Sigma\left(c_{1}\right)} H_{1}\left(c_{1}\right)<0
\end{aligned}
$$

and

$$
\begin{aligned}
\frac{d F_{c_{1}}^{\prime}(0)}{d c_{1}} & =\frac{1}{W_{H_{0} H_{1}}\left(c_{1}\right)} \frac{\lambda}{r-\mu} H_{0}^{\prime}\left(c_{1}\right)>0, \\
\frac{d^{2} F_{c_{1}}^{\prime}(0)}{d^{2} c_{1}} & =\frac{1}{W_{H_{0} H_{1}}\left(c_{1}\right)} \frac{2 \lambda}{\Sigma\left(c_{1}\right)} H_{0}\left(c_{1}\right)>0 .
\end{aligned}
$$

Since $\lim _{c_{1} \downarrow 0} F_{c_{1}}(0)=\frac{\alpha}{r-\mu}>\frac{\omega \alpha}{r-\mu}$ and $\lim _{c_{1} \downarrow} F_{c_{1}}^{\prime}(0)=1<p$, it follows from Lemma 2 that there exists a unique $\hat{c}_{1}>0$ such that $F_{\hat{c}_{1}}(0)=\frac{\omega \alpha}{r-\mu}$, and that there exists a unique $\tilde{c}_{1}>0$ such that $F_{\tilde{c}_{1}}^{\prime}(0)=p$. Note that:

1. $\hat{c}_{1}$ satisfies $\hat{c}_{1}<\frac{\alpha}{\lambda}(1-\omega)$. Indeed, the concavity property implies $F_{c_{1}}(0)<F_{c_{1}}\left(c_{1}\right)-c_{1}$. A computation yields $F_{c_{1}}\left(c_{1}\right)-c_{1} \leq \frac{\omega \alpha}{r-\mu}$ iff $c_{1} \geq \frac{\alpha}{\lambda}(1-\omega)$, (in the case $\lambda>r-\mu$, we have $\frac{\alpha}{\lambda}(1-\omega)<\frac{\alpha}{\lambda+\mu-r}$, and thus the assumption of assertion (ii) of lemma 1 is satisfied).

2. $\hat{c}_{1}>\tilde{c}_{1}$ if and only if $F_{\hat{c}_{1}}^{\prime}(0)>p$. Furthermore, Lemma 1 along with the fact that $F_{c_{1}}^{\prime}\left(c_{1}\right)=1$ implies that if $c_{1} \geq \tilde{c}_{1}$, there exists a unique $c_{p}\left(c_{1}\right) \in\left[0, c_{1}\right)$ such that $F_{c_{1}}^{\prime}\left(c_{p}\left(c_{1}\right)\right)=p$. This corresponds to the unique maximum over $[0, \infty)$ in case (i) of Lemma 1, (resp. over $\left[0, c_{1}\right)$ in case (ii) of Lemma 1) of the function $c \mapsto F_{c_{1}}(c)-p(c+\phi)$. By construction, we have that $c_{p}\left(\tilde{c}_{1}\right)=0$.

The remaining of the proof of Proposition 5 coincides with the proof of Proposition A1 in DMRV (2011). This leads to the two cases:

1. If $F_{\hat{c}_{1}}^{\prime}(0) \leq p$, then $\left(F, c^{*}\right)=\left(F_{\hat{c}_{1}}, \hat{c}_{1}\right)$ solves the variational system (18), (19), (22). Note that by construction $F(0)=\frac{\omega \alpha}{r-\mu}$. We will say that issuance costs are high.

2. If $F_{\hat{c}_{1}}^{\prime}(0)>p$, then there exists a unique $c_{1}^{\prime} \in\left(\tilde{c}_{1}, \hat{c}_{1}\right)$ such that $F_{c_{1}^{\prime}}(0)=F_{c_{1}^{\prime}}\left(c_{p}\left(c_{1}^{\prime}\right)\right)-$ $p\left(c_{p}\left(c_{1}^{\prime}\right)+\phi\right)$. The pair $\left(F, c^{*}\right)=\left(F_{c_{1}^{\prime}}, c_{1}^{\prime}\right)$ solves the variational system (18), (19), (22). Lemma 2 along with $c_{1}^{\prime}<\hat{c}_{1}$ implies that $F(0)>\frac{\omega \alpha}{r-\mu}$. Furthermore, as $c_{1}^{\prime}>\tilde{c}_{1}$, the function $c \mapsto F(c)-p(c+\phi)$ reaches its maximum over $[0, \infty)$ at $\bar{c} \equiv c_{p}\left(c_{1}^{\prime}\right)$. We will say that issuance costs are low. 
Step 3 We now show that the functions $F^{*}$ and $F$ coincide. The next Lemma states that $F$ is an upper bound for $F^{*}$

Lemma 3. For any admissible policy $\left(\left(\tau_{n}\right)_{n \geq 1},\left(e_{n}\right)_{n \geq 1}, L\right)$, the solution $F$ to (18), (19), (22) satisfies

$$
F(c) \geq f\left(c ;\left(\tau_{n}\right)_{n \geq 1},\left(e_{n}\right)_{n \geq 1}, L\right) ; c>0 .
$$

The proof of Lemma 3 is standard and follows from Lemma A4 in DMRV (2011). To prove that $F=F^{*}$, it thus remains to construct an admissible policy, the value of which coincides with the function $F$. To this end, we consider the scaled cash reserve process $C^{*}$ defined as the solution to the Skorokhod problem

$$
\begin{aligned}
C_{t}^{*}= & m+\int_{0}^{t}\left(\alpha+C_{s}^{*}(r-\lambda-\mu)\right) d s+\sqrt{\sigma_{A}^{2} C_{s}^{* 2}-2 \rho \sigma_{X} \sigma_{A} C_{s}^{*}+\sigma_{X}^{2}} d W_{s}^{C} \\
& +\sum_{n \geq 1} \bar{c} 1_{\left\{\tau_{n}^{*} \leq t\right\}}-L_{t}^{*}, \\
C_{t}^{*} \leq & c^{*}, \\
L_{t}^{*}= & \int_{0}^{t} 1_{\left\{C_{s}^{*}=c^{*}\right\}} d L_{s}^{*},
\end{aligned}
$$

where the sequence of stopping times $\left(\tau_{n}^{*}\right)_{n \geq 1}$ is recursively defined by

$$
\tau_{0}^{*} \equiv 0, \quad \tau_{n}^{*} \equiv \inf \left\{t>\tau_{n-1}^{*} \mid C_{t^{-}}^{*}=0 \text { and } C_{t}^{*}=\bar{c}>0\right\} ; \quad n \geq 1,
$$

with inf $\emptyset \equiv \infty$ by convention. Standard results on the Skorokhod problem imply that there exists a unique solution $\left(C^{*}, L^{*}\right)$ to (A17)-(A20). Condition (A19) requires that cumulative scaled dividends increase only when the scaled cash reserves reach the boundary $c^{*}$. Conditions (A17)-(A18) show that this causes the scaled cash reserves to be reflected back at $c^{*}$. Two cases can arise. If issuance costs are high, $\bar{c}=0$ and the project is liquidated as soon as $C^{*}$ drops to zero, so that $\tau_{0}^{*}=\inf \left\{t \geq 0 \mid C_{t^{-}}^{*}=0\right\}<\infty, \tilde{\mathbb{P}}$-almost surely. If issuance costs are low, then $\bar{c}=c_{p}\left(c^{*}\right)>0$, and the process $C^{*}$ discontinuously jumps to $\bar{c}$ each time it drops down to zero, so that $\tau_{0}^{*}=\infty, \tilde{\mathbb{P}}$-almost surely. This corresponds to a situation in which, for any $n \geq 1, e^{*}=F^{*}(\bar{c})-F^{*}(0)=p(\bar{c}+\phi)$. Drawing on DMRV (2011), we obtain

Proposition 6. The value function $F^{*}$ for problem (A3) coincides with the function $F$ solution to (18), (19), (22) that is twice continuously differentiable over $(0, \infty)$. The optimal issuance and dividend policies are given by $\left(\left(\tau_{n}^{*}\right)_{n \geq 1},\left(e_{n}^{*}\right)_{n \geq 1}, L^{*}\right)$, where

$$
\tau_{n}^{*}=\infty, \quad i_{n}^{*}=0 ; \quad n \geq 1
$$

if issuance costs are high, and

$$
\tau_{n}^{*}=\inf \left\{t>\tau_{n-1} \mid C_{t^{-}}^{*}=0\right\}, \quad e_{n}^{*}=p(\bar{c}+\phi) ; \quad n \geq 1
$$

if issuance costs are low.

Finally, Proposition 6 together with Proposition 4 leads to Proposition 1. 


\section{B. Comparative statics}

To make the dependence of $F, \bar{c}$, and $c^{*}$ on $\theta$ explicit, we write $F=F(., \theta), \bar{c}=\bar{c}(\theta)$, and $c^{*}=c^{*}(\theta)$. Proposition 7 below and its corollaries establish Proposition 2.

Proposition 7. Let $\theta$ be one of the deep parameters of the model.

1. If issuance costs are high (liquidation case), then firm value satisfies

$$
\begin{aligned}
\frac{\partial F}{\partial \theta}(c, \theta)= & \mathbb{E}_{c}\left[\int _ { 0 } ^ { \tau _ { 0 } } e ^ { - ( r - \mu ) t } \left(-\frac{\partial[r-\mu]}{\partial \theta} F\left(C_{t}^{*}, \theta\right)+\frac{\partial\left[\alpha+(r-\lambda-\mu) C_{t}^{*}\right]}{\partial \theta} \frac{\partial F}{\partial c}\left(C_{t}^{*}, \theta\right)\right.\right. \\
& \left.\left.+\frac{1}{2} \frac{\partial\left[\sigma_{A}^{2} C_{t}^{* 2}-2 \rho \sigma_{A} \sigma_{X} C_{t}^{*}+\sigma_{X}^{2}\right]}{\partial \theta} \frac{\partial^{2} F}{\partial c^{2}}\left(C_{t}^{*}, \theta\right)\right) d t+e^{-(r-\mu) \tau} \frac{\partial[\omega \alpha /(r-\mu)]}{\partial \theta}\right] .
\end{aligned}
$$

2. If issuance costs are low (refinancing case), then firm value satisfies

$$
\begin{aligned}
\frac{\partial F}{\partial \theta}(c, \theta)= & \mathbb{E}_{c}\left[\int _ { 0 } ^ { \infty } e ^ { - ( r - \mu ) t } \left(-\frac{\partial[r-\mu]}{\partial \theta} F\left(C_{t^{-}}^{*}\right)+\frac{\partial\left[\alpha+(r-\lambda-\mu) C_{t^{-}}^{*}\right]}{\partial \theta} \frac{\partial F}{\partial c}\left(C_{t^{-}}^{*}, \theta\right)\right.\right. \\
& \left.+\frac{1}{2} \frac{\partial\left[\sigma_{A}^{2} C_{t^{-}}^{* 2}-2 \rho \sigma_{A} \sigma_{X} C_{t^{-}}^{*}+\sigma_{X}^{2}\right]}{\partial \theta} \frac{\partial^{2} F}{\partial c^{2}}\left(C_{t^{-}}^{*}, \theta\right)\right) d t \\
& \left.-\left(\frac{\partial F}{\partial \theta}(\bar{c}(\theta), \theta)-\frac{\partial F}{\partial \theta}(0, \theta)\right) \sum_{n \geq 1} e^{-r \tau_{n}^{*}}\right]
\end{aligned}
$$

3. In both the liquidation and refinancing cases, the target level of cash holdings satisfies

$$
\frac{d c^{*}(\theta)}{d \theta}=-\frac{r-\mu}{\lambda}\left(\frac{\partial F}{\partial \theta}\left(c^{*}(\theta), \theta\right)+c^{*}(\theta) \frac{\partial\left[\frac{\lambda}{r-\mu}\right]}{\partial \theta}-\frac{\partial\left[\frac{\alpha}{r-\mu}\right]}{\partial \theta}\right) .
$$

Using Proposition 7, we can measure the effects of the model parameters on the (scaled) value of an active firm and the target level of liquid reserves.

Proof of Proposition 7: We prove case 2 (refinancing case). The proof of case 1 is similar. Applying Itô's lemma, we get

$$
\begin{aligned}
e^{-(r-\mu) T} \frac{\partial F}{\partial \theta}\left(C_{T}^{*}, \theta\right)= & \frac{\partial F}{\partial \theta}(c, \theta)+\int_{0}^{T} e^{-(r-\mu) t}\left[-(r-\mu) \frac{\partial F}{\partial \theta}\left(C_{t^{-}}^{*}, \theta\right)+\mathcal{L} \frac{\partial F}{\partial \theta}\left(C_{t^{-}}^{*}, \theta\right)\right] d t \\
& +\int_{0}^{T} e^{-(r-\mu) t} \frac{\partial^{2} F}{\partial c \partial \theta}\left(C_{t^{-}}^{*}, \theta\right)\left(\left(\sigma_{X} \rho-C_{t^{-}}^{*} \sigma_{A}\right) d \tilde{W}_{t}^{P}+\sigma_{X} \sqrt{1-\rho^{2}} d W_{t}^{T}\right) \\
& -\int_{0}^{T} e^{-(r-\mu) t} \frac{\partial^{2} F}{\partial c \partial \theta}\left(C_{t^{-}}^{*}, \theta\right) d L_{t}^{*} \\
& +\sum_{t \in[0, T]} e^{-(r-\mu) t}\left(\frac{\partial F}{\partial \theta}\left(C_{t}^{*}, \theta\right)-\frac{\partial F}{\partial \theta}\left(C_{t^{-}}^{*}, \theta\right)\right)
\end{aligned}
$$


for all $T \geq 0$ and where the operator $\mathcal{L}$ is defined by

$$
\mathcal{L} u(c)=(\alpha+c(r-\lambda-\mu)) u^{\prime}(c)+\frac{1}{2}\left(\sigma_{P}^{2} c^{2}-2 \rho \sigma_{A} \sigma_{X} c+\sigma_{X}^{2}\right) u^{\prime \prime}(c) .
$$

Let us consider each term of the right hand side of (A22). We deduce from (18) that the first term of the right hand side (RHS) of (A22) satisfies

$$
\begin{aligned}
& -(r-\mu) \frac{\partial F}{\partial \theta}\left(C_{t^{-}}^{*}, \theta\right)+\mathcal{L} \frac{\partial F}{\partial \theta}\left(C_{t^{-}}^{*}, \theta\right) \\
= & -(r-\mu) \frac{\partial F}{\partial \theta}\left(C_{t^{-}}^{*}, \theta\right)+\left(\alpha+C_{t^{-}}^{*}(r-\lambda-\mu)\right) \frac{\partial^{2} F}{\partial \theta \partial c}\left(C_{t^{-}}^{*}, \theta\right) \\
& +\frac{1}{2}\left(\sigma_{A}^{2} C_{t^{-}}^{* 2}-2 \rho \sigma_{A} \sigma_{T} C_{t^{-}}^{*}+\sigma_{X}^{2}\right) \frac{\partial^{3} F}{\partial \theta \partial c^{2}}\left(C_{t^{-}}^{*}, \theta\right) \\
= & \frac{\partial[r-\mu]}{\partial \theta} F\left(C_{t^{-}}^{*}, \theta\right)-\frac{\partial\left[\alpha+C_{t^{-}}^{*}(r-\lambda-\mu)\right]}{\partial \theta} \frac{\partial F}{\partial c}\left(C_{t^{-}}^{*}, \theta\right) \\
& -\frac{1}{2} \frac{\partial\left[\sigma_{A}^{2} C_{t^{-}}^{* 2}-2 \rho \sigma_{A} \sigma_{X} C_{t^{-}}^{*}+\sigma_{X}^{2}\right]}{\partial \theta} \frac{\partial^{2} F}{\partial c^{2}}\left(C_{t^{-}}^{*}, \theta\right) .
\end{aligned}
$$

Because $\frac{\partial^{2} F}{\partial c \partial \theta}(., \theta)$ is bounded over $\left(0, c^{*}(\theta)\right]$, the third term of the RHS of (A22) is a square integrable martingale. The fourth term is identically zero. Indeed, differentiating $\frac{\partial F}{\partial c}\left(c^{*}(\theta), \theta\right)=1$ with respect to $\theta$ and using the fact that $\frac{\partial F^{2}}{\partial c^{2}}\left(c^{*}(\theta), \theta\right)=0$ yields $\frac{\partial F^{2}}{\partial c \partial \theta}\left(c^{*}(\theta), \theta\right)=0$ which, together with (A19) implies the result. Lastly, because $C^{*}$ has paths that are continuous except at the issuance dates $\left(\tau_{n}^{*}\right)_{n \geq 0}$, one has

$$
\sum_{t \in[0, T]} e^{-(r-\mu) t}\left(\frac{\partial F}{\partial \theta}\left(C_{t}^{*}, \theta\right)-\frac{\partial F}{\partial \theta}\left(C_{t^{-}}^{*}, \theta\right)\right)=\left(\frac{\partial F}{\partial \theta}(\bar{c}(\theta), \theta)-\frac{\partial F}{\partial \theta}(0, \theta)\right) \sum_{n \geq 1} e^{-r \tau_{n}^{*}} \mathbb{1}_{\tau_{n}^{*} \leq T} .
$$

Taking expectations in (A22) yields

$$
\begin{aligned}
\frac{\partial F}{\partial \theta}(c, \theta)= & \mathbb{E}_{c}\left[\int _ { 0 } ^ { T } e ^ { - ( r - \mu ) t } \left(-\frac{\partial[r-\mu]}{\partial \theta} F\left(C_{t^{-}}^{*}, \theta\right)+\frac{\partial\left[\alpha+C_{t^{-}}^{*}(r-\lambda-\mu)\right]}{\partial \theta} \frac{\partial F}{\partial c}\left(C_{t^{-}}^{*}, \theta\right)\right.\right. \\
& \left.\left.+\frac{1}{2} \frac{\partial\left[\sigma_{A}^{2} C_{t^{-}}^{* 2}-2 \rho \sigma_{A} \sigma_{X} C_{t^{-}}^{*}+\sigma_{X}^{2}\right]}{\partial \theta} \frac{\partial^{2} F}{\partial c^{2}}\left(C_{t^{-}}^{*}, \theta\right)\right) d t\right] \\
& -\left(\frac{\partial F}{\partial \theta}(\bar{c}(\theta), \theta)-\frac{\partial F}{\partial \theta}(0, \theta)\right) \sum_{n \geq 1} e^{-r \tau_{n}^{*}}+\mathbb{E}\left[e^{-(r-\mu) T} \frac{\partial F}{\partial \theta}\left(C_{T}^{*}, \theta\right)\right]
\end{aligned}
$$

To conclude, we show that $\lim _{T \rightarrow \infty} \mathbb{E}\left[e^{-(r-\mu) T} \frac{\partial F}{\partial \theta}\left(C_{T}^{*}, \theta\right)\right]=0$. Because, $\frac{\partial^{2} F}{\partial c \partial \theta}(., \theta)$ is bounded over $\left(0, c^{*}(\theta)\right]$, we have

$$
e^{-(r-\mu) T} \frac{\partial F}{\partial \theta}\left(C_{T}^{*}, \theta\right) \leq e^{-(r-\mu) T} K\left(1+C_{T}^{*}\right) \leq e^{-(r-\mu) T} K\left(1+c^{*}(\theta)\right)
$$

for all $T$, where $K$ is a positive constant, and the third inequality follows from the fact that $C_{T}^{*} \leq c^{*}(\theta) \mathbb{P}$ almost surely, thus the result. 
Differentiating equation (24) of the main text with respect to $\theta$ yields (A21).

\section{B.1. Comparative statics: parameters $\sigma_{X}, \sigma_{A}, \rho$}

Proposition 7 yields:

Corollary 1. For any $p>1$ and $\phi>0$, for any $c \in\left(0, c^{*}\right)$,

$$
\begin{array}{r}
\frac{\partial F}{\partial \sigma_{X}}\left(c, \sigma_{X}\right)=\mathbb{E}_{c}\left[\int_{0}^{\tau_{0}} e^{-(r-\mu) t}\left(-\rho \sigma_{A} C_{t^{-}}^{*}+\sigma_{X}\right) \frac{\partial^{2} F}{\partial c^{2}}\left(C_{t^{-}}^{*}, \sigma_{X}\right) d t\right] \\
\frac{\partial F}{\partial \sigma_{A}}\left(c, \sigma_{A}\right)=\mathbb{E}_{c}\left[\int_{0}^{\tau_{0}} e^{-(r-\mu) t}\left(\sigma_{A} C_{t^{-}}^{*}-\rho \sigma_{X}\right) C_{t^{-}}^{*} \frac{\partial^{2} F}{\partial c^{2}}\left(C_{t^{-}}^{*}, \sigma_{A}\right) d t\right] \\
\frac{\partial F}{\partial \rho}(c, \rho)=\mathbb{E}_{c}\left[\int_{0}^{\tau_{0}} e^{-(r-\mu) t}\left(-\sigma_{A} \sigma_{X}\right) C_{t^{-}}^{*} \frac{\partial^{2} F}{\partial c^{2}}\left(C_{t^{-}}^{*}, \rho\right) d t\right]>0
\end{array}
$$

and

$$
\frac{d c^{*}(\theta)}{d \theta}=-\frac{r-\mu}{\lambda} \frac{\partial F}{\partial \theta}\left(c^{*}(\theta), \theta\right) \quad \text { for } \theta \in\left\{\sigma_{X}, \sigma_{A}, \rho\right\}
$$

Equations (A23)-(A26) hold in the liquidation case and the refinancing case.

Proof of Corollary 1. We recall that, in the refinancing case $\tau_{0}=\infty$ a.e. The proof follows directly from Proposition 7. It remains simply to remark that, for $\theta \in\left\{\sigma_{X}, \sigma_{A}, \rho\right\}$, we have

$$
\frac{\partial F}{\partial \theta}(\bar{c}(\theta), \theta)-\frac{\partial F}{\partial \theta}(0, \theta)=0 .
$$

Equation (A27) results from differentiating $F(0, \theta)=F(\bar{c}(\theta), \theta)-p(\bar{c}(\theta)+\phi)$ with respect to $\theta$ and using the fact that $\frac{\partial F}{\partial c}(\bar{c}(\theta), \theta)=p$.

\section{B.2. Comparative statics: parameters $p, \phi$}

Corollary 2. The following holds (refinancing case):

1.

$$
\frac{\partial F}{\partial p}(c, p)=-(\bar{c}(p)+\phi) \mathbb{E}_{c}\left[\sum_{n \geq 1} e^{-r \tau_{n}^{*}}\right]<0, \quad \frac{d c^{*}(p)}{d p}=-\frac{r-\mu}{\lambda} \frac{\partial F}{\partial p}\left(c^{*}(p), p\right)>0
$$

2.

$$
\frac{\partial F}{\partial \phi}(c, \phi)=-p \sum_{n \geq 1} \mathbb{E}_{c}\left[e^{-r \tau_{n}^{*}}\right]<0, \quad \frac{d c^{*}(\phi)}{d \phi}=-\frac{r-\mu}{\lambda} \frac{\partial F}{\partial \phi}\left(c^{*}(\phi), \phi\right)>0 .
$$

Proof of Corollary 2. Direct implication of Proposition 7. 


\section{B.3. Comparative statics: parameters $\alpha, \mu$}

Corollary 3. The following holds, in the refinancing case, for all $c \in\left[0, c^{*}\right)$ :

1 .

$$
\begin{aligned}
& \frac{\partial F}{\partial \alpha}(c, \alpha)=\mathbb{E}_{c}\left[\int_{0}^{\infty} e^{-(r-\mu) t} \frac{\partial F}{\partial c}\left(C_{t^{-}}^{*}, \alpha\right) d t\right]>0, \\
& \frac{d c^{*}(\alpha)}{d \alpha}=-\frac{r-\mu}{\lambda}\left(\frac{\partial F}{\partial \alpha}\left(c^{*}(\alpha), \alpha\right)-\frac{1}{r-\mu}\right)<0 .
\end{aligned}
$$

2.

$$
\begin{aligned}
& \frac{\partial F}{\partial \mu}(c, \mu)=\mathbb{E}_{c}\left[\int_{0}^{\infty} e^{-(r-\mu) t}\left(F\left(C_{t^{-}}^{*}, \mu\right)-C_{t^{-}}^{*} \frac{\partial F}{\partial c}\left(C_{t^{-}}^{*}, \mu\right)\right) d t\right]>0, \\
& \frac{d c^{*}(\mu)}{d \mu}=-\frac{r-\mu}{\lambda}\left(\frac{\partial F}{\partial \mu}\left(c^{*}(\mu), \mu\right)-\frac{\lambda}{(r-\mu)^{2}}\left(\frac{\alpha}{\lambda}-c^{*}(\mu)\right)\right)>0 .
\end{aligned}
$$

Proof of Corollary 3. Note that equation (A27) holds for $\theta \in\{\alpha, \mu\}$. Then formulas for $\frac{\partial F}{\partial \theta}(c, \theta)$ and $\frac{d c^{*}(\theta)}{d \theta}$ with $\theta \in\{\alpha, \mu\}$ follow from Proposition 7. Let us recall that $\frac{\partial F}{\partial c}(c, \theta)>1$ over $\left[0, c^{*}\right)$ and $C_{t}^{*} \leq c^{*} \mathbb{P}$ almost surely. Thus, $\frac{\partial F}{\partial \alpha}(c, \alpha)>0$ and, for $c \in\left[0, c^{*}\right)$, we have

$$
\frac{\partial F}{\partial \alpha}(c, \alpha)=\mathbb{E}_{c}\left[\int_{0}^{\infty} e^{-(r-\mu) t} \frac{\partial F}{\partial c}\left(C_{t^{-}}^{*}, \alpha\right) d t\right]>\mathbb{E}\left[\int_{0}^{\infty} e^{-(r-\mu) t} d t\right]=\frac{1}{r-\mu},
$$

which implies $\frac{d c^{*}(\alpha)}{d \alpha}<0$. Together with the concavity of $F$ with respect to $c$, it follows also that, for all $c \in\left[0, c^{*}\right)$,

$$
F(c, \mu)-c \frac{\partial F}{\partial c}(c, \mu)>F(c, \mu)-c>0,
$$

which leads to $\frac{\partial F}{\partial \mu}(c, \mu)>0$. Noting that $c \longrightarrow F(c, \mu)-c \frac{\partial F}{\partial c}(c, \mu)$ is increasing over $\left[0, c^{*}\right]$, we get

$$
\begin{aligned}
\frac{\partial F}{\partial \mu}(c, \mu) & =\mathbb{E}_{c}\left[\int_{0}^{\infty} e^{-(r-\mu) t}\left(F\left(C_{t^{-}}^{*}, \mu\right)-C_{t^{-}}^{*} \frac{\partial F}{\partial c}\left(C_{t^{-}}^{*}, \mu\right)\right) d t\right] \\
& \left.<\mathbb{E}\left[\int_{0}^{\infty} e^{-(r-\mu) t}\left(F\left(c^{*}, \mu\right)-c^{*}\right)\right) d t\right] \\
& \left.=\mathbb{E}\left[\int_{0}^{\infty} e^{-(r-\mu) t}\left(\frac{\alpha}{r-\mu}+\left(1-\frac{\lambda}{r-\mu}\right) c^{*}-c^{*}\right)\right) d t\right]=\frac{\lambda}{(r-\mu)^{2}}\left(\frac{\alpha}{\lambda}-c^{*}\right),
\end{aligned}
$$

which implies that $\frac{d c^{*}(\mu)}{d \mu}>0$. 
Corollary 4. The following holds, in the liquidation case, for all $c \in\left[0, c^{*}\right)$ :

1 .

$$
\frac{\partial F}{\partial \alpha}(c, \alpha)=\mathbb{E}_{c}\left[\int_{0}^{\tau_{0}} e^{-(r-\mu) t} \frac{\partial F}{\partial c}\left(C_{t}^{*}, \alpha\right) d t\right]+\mathbb{E}_{c}\left[e^{-(r-\mu) \tau_{0}} \frac{\omega}{r-\mu}\right]>0
$$

The sign of $\frac{d c^{*}(\alpha)}{d \alpha}$ is indeterminate.

2.

$\frac{\partial F}{\partial \mu}(c, \mu)=\mathbb{E}_{c}\left[\int_{0}^{\tau_{0}} e^{-(r-\mu) t}\left(F\left(C_{t^{-}}^{*}, \mu\right)-C_{t^{-}}^{*} \frac{\partial F}{\partial c}\left(C_{t^{-}}^{*}, \mu\right)\right) d t\right]+\mathbb{E}_{c}\left[e^{-(r-\mu) \tau_{0}} \frac{\omega \alpha}{(r-\mu)^{2}}\right]>0$.

The sign of $\frac{d c^{*}(\mu)}{d \mu}$ is indeterminate.

Proof of Corollary 4. Direct application of Proposition 7.

\section{Proof of Proposition 3}

Note that,

$$
\begin{aligned}
& \sup _{m_{0} \geq 0, \tau \in \mathcal{T}} \mathbb{E}\left[e^{-r \tau}\left(V\left(A_{\tau}, m_{0}\right)-p\left(m_{0}+I\right)-p \phi A_{\tau}\right)\right] \\
= & \sup _{\tau \in \mathcal{T}} \mathbb{E}\left[\max _{m_{0} \geq 0} \mathbb{E}\left[e^{-r \tau}\left(V\left(A_{\tau}, m_{0}\right)-p\left(m_{0}+I\right)-p \phi A_{\tau}\right) \mid \mathcal{F}_{\tau}\right]\right] .
\end{aligned}
$$

If issuance costs are low, then $F(0)=\max _{c \in[0, \infty)}(F(c)-p(c+\phi))=F(\bar{c})-p(\bar{c}+\phi)>\frac{\omega \alpha}{r-\mu}$ and the mapping $m \longrightarrow V\left(A_{t}, m\right)-p(m+I)-p \phi A_{t}$ reaches its maximum at $m_{0}=\bar{c} A_{t}$. Thus, (A28) can be written in the form

$$
\begin{aligned}
\sup _{\tau \in \mathcal{T}} \mathbb{E}\left[e^{-r \tau}\left(V\left(A_{\tau}, \bar{c} A_{\tau}\right)-p\left(\bar{c} A_{\tau}+I\right)-p \phi A_{\tau}\right)\right] & \left.=\sup _{\tau \in \mathcal{T}} \mathbb{E}\left[e^{-r \tau}(F(\bar{c})-p(\bar{c}+\phi)) A_{\tau}-p I\right)\right] \\
& =\sup _{\tau \in \mathcal{T}} \mathbb{E}\left[e^{-r \tau}\left(F(0) A_{\tau}-p I\right)\right] .
\end{aligned}
$$

Standard computations yield the result.

If issuance costs are high, then $F(0)=\frac{\omega \alpha}{r-\mu}$ and the mapping $m \longrightarrow V\left(A_{t}, m\right)-p(m+$ $I)-p \phi A_{t}$ is decreasing. Thus, no cash is raised at the time of investment (in addition to the investment cost I) and (A28) can be written in the form

$$
\left.\sup _{\tau \in \mathcal{T}} \mathbb{E}\left[e^{-r \tau}\left(V\left(A_{\tau}, 0\right)-p I-p \phi A_{\tau}\right)\right]=\sup _{\tau \in \mathcal{T}} \mathbb{E}\left[e^{-r \tau}(F(0)-p \phi) A_{\tau}-p I\right)\right] .
$$

If $F(0)>p \phi$, then standard computations leads to (51). Clearly, if $F(0) \leq p \phi$, the option value to invest is worthless 


\section{References}

Abel, A. 2015. Optimal debt and profitability in the tradeoff theory. Working paper, University of Pennsylvania.

Abel, A., and J. Eberly. 1994. A unified model of investment under uncertainty. American Economic Review 84:1369-1384.

Almeida, H., M. Campello, and M. S. Weisbach. 2004. The cash flow sensitivity of cash. Journal of Finance 59:1777-1804.

Bansal, R., R. Dittmar, and D. Kiku. 2008. Cointegration and consumption risks in asset returns. Review of Financial Studies 22:1343-1375.

Beveridge, S., and C. Nelson. 1981. A new approach to decomposition of economic times series into permanent and transitory components with particular attention to measurement of the business cycle. Journal of Monetary Economics 7:151-174.

Biais, B., T. Mariotti, G. Plantin, and J. Rochet. 2007. Dynamic security design: Convergence to continuous time and asset pricing implications. Review of Economic Studies 74:345-390.

Biais, B., T. Mariotti, and J. Rochet. 2013. Dynamic financial contracting. Advances in Economics and Econometrics, Cambridge University Press pp. 125-171.

Blundell, R., L. Pistaferri, and I. Preston. 2008. Consumption inequality and partial insurance. American Economic Review 98:1887-1921.

Boehmer, E., and J. Wu. 2013. Short selling and the price discovery process. Review of Financial Studies 26:287-322.

Bolton, P., H. Chen, and N. Wang. 2011. A unified theory of Tobin's q, corporate investment, financing, and risk management. Journal of Finance 66:1545-1578.

Bolton, P., H. Chen, and N. Wang. 2013. Market timing, investment, and risk management. Journal of Financial Economics 109:40-62.

Bolton, P., N. Wang, and J. Yang. 2015. Investment under uncertainty and the value of real and financial flexibility. Working paper, Columbia University.

Boyle, G., and G. Guthrie. 2003. Investment, uncertainty, and liquidity. Journal of Finance $58: 2143-2166$.

Brennan, M., and A. Subrahmanyam. 1996. Market microstructure and asset pricing: On the compensation for illiquidity in stock returns. Journal of Financial Economics 41:441-464.

Byun, S., V. Polkovnichenko, and M. Rebello. 2016. Corporate savings and investment with transitory and persistent shocks. Working paper, University of Texas. 
Carlson, M., A. Fisher, and R. Giammarino. 2006. Corporate investment and asset price dynamics: Implications for SEO event-studies and long-run performance. Journal of Finance 61:1009-1034.

Chang, X., S. Dasgupta, G. Wong, and J. Yao. 2014. Cash-flow sensitivities and the allocation of internal cash flow. Review of Financial Studies 27:3628-3657.

Cocco, J., F. Gomes, and P. Maenhout. 2005. Consumption and portfolio choice over the life cycle. Review of Financial Studies 18:491-533.

Cochrane, J. 1994. Permanent and transitory components of GNP and stock prices. Quarterly Journal of Economics 109:241-265.

Cohen, R., P. Gompers, and T. Vuolteenaho. 2002. Who underreacts to cash-flow news? Evidence from trading between individuals and institutions. Journal of Financial Economics 66:409-462.

Décamps, J.-P., T. Mariotti, J.-C. Rochet, and S. Villeneuve. 2011. Free cash flow, issuance costs, and stock prices. Journal of Finance 66:1501-1544.

DeMarzo, P., M. Fishman, Z. He, and N. Wang. 2012. Dynamic agency and the q theory of investment. Journal of Finance 67:2295-2340.

DeMarzo, P., and Y. Sannikov. 2006. Optimal security design and dynamic capital structure in a continuous-time agency model. Journal of Finance 61:2681-2724.

Dixit, A. K., and R. S. Pindyck. 1994. Investment under Uncertainty. Princeton, NJ: Princeton University Press.

Dumas, B. 1992. Super contact and related optimality conditions. Journal of Economic Dynamics and Control 15:675-685.

Frankel, R., and L. Litov. 2009. Earnings persistence. Journal of Accounting and Economics 47:182-190.

Garleanu, N., L. Kogan, and S. Panageas. 2012a. Displacement risk and asset returns. Journal of Financial Economics 105:491-510.

Garleanu, N., S. Panageas, and J. Yu. 2012b. Technological growth and asset pricing. Journal of Finance 67:1265-1292.

Glosten, L., and L. Harris. 1988. Estimating the components of the bid/ask spread. Journal of Financial Economics 21:123-142.

Glover, B. 2016. The expected cost of default. Journal of Financial Economics 119:284-299.

Goldstein, R., N. Ju, and H. Leland. 2001. An EBIT-based model of dynamic capital structure. Journal of Business 74:483-512. 
Gorbenko, A. S., and I. A. Strebulaev. 2010. Temporary versus permanent shocks: Explaining corporate financial policies. Review of Financial Studies 23:2591-2647.

Gottschalk, P., and R. Moffitt. 2009. The rising instability of U.S. earnings. Journal of Economic Perspectives 23:3-24.

Grenadier, S. R., and A. Malenko. 2010. A Bayesian approach to real options: The case of distinguishing between temporary and permanent shocks. Journal of Finance 65:19491986.

Grenadier, S. R., and A. Malenko. 2011. Real options signaling games with applications to corporate finance. Review of Financial Studies 24:3393-4036.

Gryglewicz, S. 2011. A theory of corporate financial decisions with liquidity and solvency concerns. Journal of Financial Economics 99:365-384.

Guiso, L., L. Pistaferri, and F. Schivardi. 2005. Insurance within the firm. Journal of Political Economy 113:1054-1087.

Hackbarth, D., J. Miao, and E. Morellec. 2006. Capital structure, credit risk, and macroeconomic conditions. Journal of Financial Economics 82:519-550.

Hamilton, J. 1994. Time Series Analysis. Princeton, NJ: Princeton University Press.

He, Z. 2009. Optimal executive compensation when firm size follows a geometric brownian motion. Review of Financial Studies 22:859-892.

Hugonnier, J., S. Malamud, and E. Morellec. 2015. Capital supply uncertainty, cash holdings, and investment. Review of Financial Studies 28:391-445.

Kogan, L., and D. Papanikolaou. 2013. Firm characteristics and stock returns: The role of investment-specific shocks. Review of Financial Studies 26:2718-2759.

Kogan, L., and D. Papanikolaou. 2014. Growth opportunities, technology shocks, and asset prices. Journal of Finance 69:675-718.

Lambrecht, B. 2004. The timing and terms of mergers motivated by economies of scale. Journal of Financial Economics 72:41-62.

Lee, B.-S., and O. M. Rui. 2007. Time-series behavior of share repurchases and dividends. Journal of Financial and Quantitative Analysis 42:119-142.

Leland, H. E. 1998. Agency costs, risk management, and capital structure. Journal of Finance 53:1213-1243.

Manso, G. 2008. Investment reversibility and the agency cost of debt. Econometrica 76:437442.

McDonald, R., and J. Siegel. 1986. The value of waiting to invest. Quarterly Journal of Economics 101:707-728. 
Meghir, C., and L. Pistaferri. 2004. Income variance dynamics and heterogeneity. Econometrica 72:1-32.

Mello, A., and J. Parsons. 2000. Hedging and liquidity. Review of Financial Studies 13:127153.

Mirantes, A., J. Poblacion, and G. Serna. 2015. Commodity derivative valuation under a factor model with time-varying market prices of risk. Review of Derivatives Research 18:75-93.

Morellec, E., B. Nikolov, and N. Schürhoff. 2012. Corporate governance and capital structure dynamics. Journal of Finance 67:803-848.

Morellec, E., and N. Schürhoff. 2011. Corporate investment and financing under asymmetric information. Journal of Financial Economics 99:262-288.

Moreno-Bromberg, S., and J.-C. Rochet. 2014. Market frictions and corporate finance: An overview paper. Mathematics and Financial Economics 8:355-381.

Opler, T., L. Pinkowitz, R. Stulz, and R. Williamson. 1999. The determinants and implications of corporate cash holdings. Journal of Financial Economics 52:3-46.

Rampini, A., A. Sufi, and S. Viswanathan. 2014. Dynamic risk management. Journal of Financial Economics 111:271-296.

Reinhart, C., and P. Wickham. 1994. Commodity prices: Cyclical weakness or secular decline? IMF Staff Papers 41:175-213.

Riddick, L., and T. Whited. 2009. The corporate propensity to save. Journal of Finance 64:1729-1766.

Schwartz, E., and J. Smith. 2000. Short-term variations and long-term dynamics in commodity prices. Management Science 46:893-911.

Stokey, N. 2009. The Economics of Inaction. Princeton, NJ: Princeton University Press.

Strebulaev, I., and T. Whited. 2012. Dynamic models and structural estimation in corporate finance. Foundations and Trends in Finance 6:1-163.

Strebulaev, I. A. 2007. Do tests of capital structure theory mean what they say? Journal of Finance 62:1747-1787.

Sufi, A. 2009. Bank lines of credit in corporate finance: An empirical analysis. Review of Financial Studies 22:1057-1088.

Tufano, P. 1996. Who manages risk? An empirical examination of risk management practices in the gold mining industry. Journal of Finance 51:1097-1137. 